\title{
Sexual Conflict in Hermaphrodites
}

\author{
Lukas Schärer ${ }^{1}$, Tim Janicke ${ }^{2}$, and Steven A. Ramm ${ }^{3}$ \\ ${ }^{1}$ Evolutionary Biology, Zoological Institute, University of Basel, 4051 Basel, Switzerland \\ ${ }^{2}$ Centre d'Écologie Fonctionnelle et Évolutive, CNRS UMR 5175, 34293 Montpellier Cedex 05, France \\ ${ }^{3}$ Evolutionary Biology, Bielefeld University, 33615 Bielefeld, Germany \\ Correspondence: lukas.scharer@unibas.ch
}

Hermaphrodites combine the male and female sex functions into a single individual, either sequentially or simultaneously. This simple fact means that they exhibit both similarities and differences in the way in which they experience, and respond to, sexual conflict compared to separate-sexed organisms. Here, we focus on clarifying how sexual conflict concepts can be adapted to apply to all anisogamous sexual systems and review unique (or especially important) aspects of sexual conflict in hermaphroditic animals. These include conflicts over the timing of sex change in sequential hermaphrodites, and in simultaneous hermaphrodites, over both sex roles and the postmating manipulation of the sperm recipient by the sperm donor. Extending and applying sexual conflict thinking to hermaphrodites can identify general evolutionary principles and help explain some of the unique reproductive diversity found among animals exhibiting this widespread but to date understudied sexual system.

$\mathrm{C}$ onceptual and empirical work on sexual conflict is dominated by studies on gonochorists (species with separate sexes) (e.g., Parker 1979, 2006; Rice and Holland 1997; Holland and Rice 1998; Rice and Chippindale 2001; Chapman et al. 2003; Arnqvist and Rowe 2005; Rice et al. 2006), and the same is true for other evolutionary aspects of sexual reproduction, such as sexual selection (e.g., Andersson 1994; Shuster and Wade 2003) and, to a lesser extent, sex allocation (e.g., Charnov 1982; Hardy 2002; West 2009). The fundamental asymmetry from which sexual conflict emerges is ultimately rooted in the evolution of anisogamy, which may itself have resulted from a primordial sexual conflict over allocation to gamete provisioning. Specifically, the (proto)male sexual strategy of making more but smaller gametes-driven by (proto)sperm competitionlikely forced the (proto)female sexual strategy into investing more resources per gamete (Parker et al. 1972; Parker 1978, 1979, 2011, 2014). In different species, the male and female sexual strategies can be distributed over individuals in various ways (Hamilton 1967; Charnov 1982; Munday et al. 2006a; Schärer 2009; Weeks 2012). In the most familiar-gonochorismthey are always confined to different individuals, namely, males and females, as exemplified by some of the best-studied animal groups (e.g., insects, birds, and mammals). But another way-hermaphroditism, in which every individual can exhibit both sexual strategies-is in fact very widespread, occurring in $\sim 70 \%$ of

Editors: William R. Rice and Sergey Gavrilets

Additional Perspectives on The Genetics and Biology of Sexual Conflict available at www.cshperspectives.org

Copyright (C) 2015 Cold Spring Harbor Laboratory Press; all rights reserved; doi: 10.1101/cshperspect.a017673

Cite this article as Cold Spring Harb Perspect Biol 2015;7:a017673 
L. Schärer et al.

animal phyla (Jarne and Auld 2006) and $>90 \%$ of plant genera (Renner and Ricklefs 1995). Although models for the evolution of anisogamy have tended to assume gonochorism (e.g., Parker et al. 1972; Lessells et al. 2009; Lehtonen and Kokko 2011; Togashi and Cox 2011), which of these "sexual systems" is actually ancestral remains an open question (Ghiselin 1969; Eppley and Jesson 2008; Iyer and Roughgarden 2008; Ryan et al. 2013; Riesgo et al. 2014).

Here, we show that sexual conflict thinking has equal validity when applied to hermaphroditic taxa (Table 1). In fact, some of the earliest insights about sexual conflict have come from the hermaphrodite literature. In a far-reaching paper published in the same year as Parker's (1979) influential book chapter, Charnov (1979) pointed out that hermaphrodites experience sexual ("male-female") conflicts over mating and fertilization, favoring, for example, the evolution of (1) manipulative seminal fluids that stimulate egg laying and prevent remating (including the disruption of the partner's male function), (2) female control of incoming ejaculate components, (3) postcopulatory female choice (later called cryptic female choice; Thornhill 1983; Eberhard 1985), and (4) male strategies-including traumatic insemination-to bypass female control. Clearly, these insights have very general relevance to all sexual systems and likely arose from the realiza- tion around this time that conflicts are an integral part of the evolution of sexual reproduction (e.g., Parker 1970, 1978, 1979; Trivers 1972, 1974; Dawkins 1976; see also Parker 2006). Unfortunately, many people working on sexual conflict in gonochorists still appear surprisingly unaware of Charnov's landmark paper (see also Schärer and Janicke 2009).

We wish to advocate a more inclusive approach to studying evolutionary reproductive biology, which aims at understanding the sexes-and how they are distributed over different individuals-from first principles (see also Schärer et al. 2012; Parker and Birkhead 2013). Thus, rather than seeing sexual conflict in hermaphrodites as a special case, we believe that studying sexual conflict in a range of different sexual systems is essential for deriving general principles of the evolution of anisogamy and its consequences.

The current bias in sexual conflict thinking probably in part reflects an uncertainty among researchers over how to think about the male and female sexual strategies in reproduction when they appear in one and the same individual. We therefore begin by outlining how some of the established (gonochorist-specific) sexual conflict concepts can be broadened to encompass not only hermaphrodites, but arguably all anisogamous sexual systems (Table 1), before briefly introducing how hermaphrodites parti-

Table 1. Important concepts of sexual conflict as commonly defined in the literature

\begin{tabular}{|c|c|c|c|}
\hline Concept & Common definition & Broadened definition & Note for hermaphrodites \\
\hline $\begin{array}{l}\text { Sexual conflict }{ }^{\mathrm{a}} \\
\quad(\text { Parker } 1979, \\
\text { p. } 124)\end{array}$ & $\begin{array}{l}\text { "a conflict between the } \\
\text { evolutionary interests of } \\
\text { individuals of the two } \\
\text { sexes"b }\end{array}$ & $\begin{array}{l}\text { A conflict between the } \\
\text { evolutionary interests } \\
\text { of a sperm donor and } \\
\text { a sperm recipient }{ }^{c}\end{array}$ & $\begin{array}{l}\text { Most individuals act in both } \\
\text { sexual roles, either at } \\
\text { different life stages, in } \\
\text { alternating matings, or } \\
\text { simultaneously in reciprocal } \\
\text { matings }\end{array}$ \\
\hline $\begin{array}{l}\text { Primordial } \\
\text { sexual } \\
\text { conflict }^{\mathrm{d}} \\
\text { (Parker 1978, } \\
\text { p. } 25 \mathrm{f})\end{array}$ & $\begin{array}{l}\text { "[Because of the evolution } \\
\text { of anisogamy] females are } \\
\text { forced into providing all of } \\
\text { the parental investment for } \\
\text { the zygote. This represents } \\
\text { the primordial sexual } \\
\text { conflict" }\end{array}$ & $\begin{array}{l}\text { Because of the evolution } \\
\text { of anisogamy the sperm } \\
\text { recipient is forced into } \\
\text { providing all of the } \\
\text { parental investment for } \\
\text { the zygote. This } \\
\text { represents the primordial } \\
\text { sexual conflict }\end{array}$ & $\begin{array}{l}\text { It is currently unclear whether } \\
\text { the evolution of anisogamy } \\
\text { occurred in gonochorists, } \\
\text { hermaphrodites, or both } \\
\text { Given current sex allocation } \\
\text { theory, the "cost of } \\
\text { anisogamy" might often be } \\
\text { lower in hermaphrodites }\end{array}$ \\
\hline
\end{tabular}

Continued 
Table 1. Continued

\begin{tabular}{|c|c|c|c|}
\hline Concept & Common definition & Broadened definition & Note for hermaphrodites \\
\hline $\begin{array}{l}\text { Mating conflict } \\
\text { (Parker 2006, } \\
\text { p. 237) }\end{array}$ & $\begin{array}{l}\text { "Mating conflicts relate to } \\
\text { asymmetries between the } \\
\text { sexes in the benefits of } \\
\text { mating versus its costs"e }\end{array}$ & $\begin{array}{l}\text { Mating conflicts relate to } \\
\text { asymmetries between } \\
\text { acting as a sperm donor } \\
\text { or sperm recipient in the } \\
\text { benefits of mating versus } \\
\text { its costs }\end{array}$ & $\begin{array}{l}\text { Asymmetries may lead to } \\
\text { identical sex role preferences } \\
\text { and thus incompatible } \\
\text { mating interests } \\
\text { In unilateral matings, one } \\
\text { mate has to assume the } \\
\text { nonpreferred role, resulting } \\
\text { in a behavioral conflict }{ }^{\mathrm{f}}\end{array}$ \\
\hline $\begin{array}{l}\text { Intralocus sexual } \\
\text { conflict (Rice } \\
\text { et al. } 2006, \\
\text { p. } 287 \text { ) }\end{array}$ & $\begin{array}{l}\text { "occurs when there is a } \\
\text { negative correlation } \\
\text { between the selection } \\
\text { coefficients of the same } \\
\text { allele when expressed in } \\
\text { males and females" }\end{array}$ & $\begin{array}{l}\text { Occurs when there is a } \\
\text { negative correlation } \\
\text { between the selection } \\
\text { coefficients of the same } \\
\text { allele when expressed in } \\
\text { a sperm donor and a } \\
\text { sperm recipient }\end{array}$ & $\begin{array}{l}\text { Individuals often act as both } \\
\text { donors and recipients, so } \\
\text { much of this represents } \\
\text { intraindividual trade-offs } \\
\text { Variance in reproductive } \\
\text { success and/or linkage to } \\
\text { sex allocation might } \\
\text { maintain antagonistic } \\
\text { variation }\end{array}$ \\
\hline $\begin{array}{l}\text { Interlocus sexual } \\
\text { conflict } \\
\text { (Arnqvist and } \\
\text { Rowe 2005, } \\
\text { p. 217) }\end{array}$ & $\begin{array}{l}\text { "[occurs] when an allelic } \\
\text { substitution at one locus } \\
\text { expressed in one sex } \\
\text { compromises the genetic } \\
\text { interests of individuals of } \\
\text { the other sex and thus } \\
\text { selects for a new allele at an } \\
\text { interacting locus expressed } \\
\text { in the latter sex" }\end{array}$ & $\begin{array}{l}\text { Occurs when an allelic } \\
\text { substitution at one locus } \\
\text { expressed in one } \\
\text { individual compromises } \\
\text { the genetic interests of } \\
\text { its mates and thus selects } \\
\text { for a new allele at an } \\
\text { interacting locus } \\
\text { expressed in those mates }\end{array}$ & $\begin{array}{l}\text { Given that most individuals } \\
\text { act as both sperm donors } \\
\text { and recipients, avoiding } \\
\text { exposure to such sexual } \\
\text { conflicts is difficult }\end{array}$ \\
\hline
\end{tabular}

The concepts are broadened (bold indicates changed text) to include all anisogamous sexual systems. Note that the terms sperm donor and sperm recipient can be used to talk about mating interactions in all anisogamous sexual systems (including those with external fertilization), as each mating necessarily involves a donor and a recipient (for plants, "sperm" can be replaced by "pollen").

aParker (1970), although not using the term "sexual conflict," clearly adopts sexual conflict thinking, stating: "Provided that the [mating] plug confers a sexual selective advantage on the male which outweighs its natural selective disadvantage [on both male and female], it should evolve or be maintained. Resultant modifications within the female to prevent or reduce the disadvantageous effects of the plug might be expected; these adaptations may conflict with the line of adaptation in the male sex" (p. 559).

'Parker (2006) suggests retaining this "broad” definition, stating: “. . sexual conflict is present in all forms of female choice involving the rejection of some males, whether rejection occurs because they are not attractive enough or because of the costs they impose" and ". . . it is best to retain the simple broad definition ..., and to recognize that it applies to many different biological circumstances" (p. 236).

"Charnov (1979) describes "male-female conflict" in hermaphrodites, stating: "There must often exist a conflict of interest between mating partners-as a recipient each should be inclined to accept sperm (not necessarily for fertilization of its own eggs) to give its sperm away. As a donor, one should be selected to induce one's partner to use the new sperm in fertilization" (p. 2482).

${ }^{\mathrm{d}}$ Parker et al. (1972) posit that the evolution of anisogamy involves a ( primordial) sexual conflict, stating: "Ovum producers are forced into an evolutionary impasse" and "The relationship between sperm and ova is not dissimilar from the relationship between parasite and host- the parasitic sperm ( producers) dependent upon and propagating at the expense of the host ovum (producers)" (p. 549).

${ }^{\mathrm{e}}$ Parker (2006) goes on to say that "[Mating conflicts] may be precopulatory, for instance, concerning mating decisions (Trivers 1972; Dawkins 1976; Parker 1979), or postcopulatory, for instance, concerning sperm use (Thornhill 1983; Eberhard $1985) "$ ( p. 237), both of which were also pointed out by Charnov (1979).

fWethington and Dillon (1996) called this "gender conflict" (p. 1108); we see no advantage in this term, because similar conflicts may also apply to reciprocally mating species.

${ }^{\mathrm{g}}$ Arnqvist and Rowe (2005) attribute this definition to Rice and Holland (1997), but this precise wording does not appear in that paper. 
L. Schärer et al.

tion resources between the male and female sex functions (i.e., sex allocation), which is important to understand sexual conflict in these organisms. We then take stock of what we do know and do not know about sexual conflictfirst in sequential hermaphrodites, and then in simultaneous hermaphrodites—with the aim of illuminating general principles and attempting to understand what is similar and what is different about sexual conflict when it occurs in different sexual systems. Given limitations on space and our own expertise, we confine our discussion to hermaphroditic animals, but emphasize here that plants undoubtedly also offer tremendous promise to expand our understanding of sexual conflict (e.g., Charnov 1979; Bernasconi et al. 2004; Arnqvist and Rowe 2005; Lankinen and Larsson 2009; Madjidian et al. 2012).

\section{SEXUAL CONFLICT THINKING IN HERMAPHRODITES}

Conventionally, evidence for both intra- and interlocus sexual conflict relies on measuring fitness effects in two types of individuals that must, by definition, have opposite sexes (Table 1). So, a difficulty for thinking about sexual conflicts in hermaphrodites is that individuals are not of two types, but either change from one type to the other (sequential hermaphrodites) or are both types at the same time (simultaneous hermaphrodites), and thus each individual has two potential routes to fitness (Fig. 1). The definitions can readily be adapted by simply replacing "male" with "sperm donor" and "female" with "sperm recipient" (Table 1), but this alone does not suffice to understand these phenomena in hermaphrodites, because (1) an individual often acts as both sperm donor and recipient, and (2) its actions often affect its partners as both sperm donors and recipients. This means there are some fundamental differences in the nature of, and likely responses to, sexual conflict compared to gonochorists.

Thinking about interlocus sexual conflict, at least initially, seems less problematic, as this simply represents conflict between two interacting mating partners, the sperm donor and the sperm recipient (Charnov 1979), and much of the literature we discuss below follows this rationale. A necessary qualification for hermaphrodites, however, is that-because of the dual routes to fitness (Fig. 1) -interactions with a mate could affect an individual's male fitness, its female fitness, or both (e.g., via reduced survival). Moreover, sex allocation trade-offs and other evolutionary links between male and female fitness, which occur in both sequential and simultaneous hermaphrodites (see below), mean that one cannot just assume that an individual is affected by sexual conflict in only one
A

Gonochorists

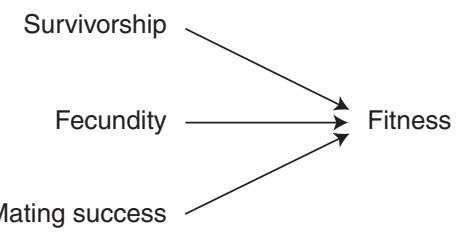

B

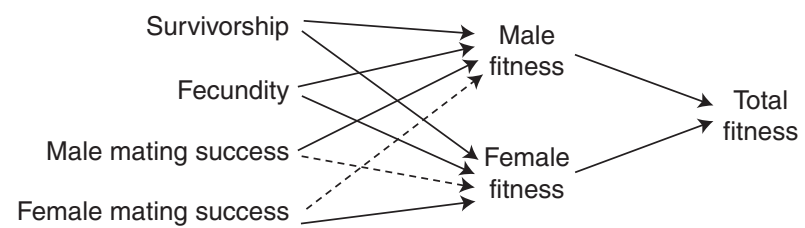

Figure 1. Two routes to fitness in hermaphrodites. (A) In gonochorists (species with separate sexes), fitness can be divided into three main components, namely, survivorship, fecundity, and mating (including fertilization) success (modified from Arnqvist and Rowe 2005). (B) In hermaphrodites, these components contribute to total fitness through both the male and female sex function. Note that in hermaphrodites, fecundity could further be split into separate male and female components that may trade off with each other. And, although in sequential hermaphrodites male and female mating success happens during nonoverlapping time periods, they may be constrained to be identical in simultaneous hermaphrodites with reciprocal mating. Finally, male mating success could affect female fitness (and vice versa, dashed arrows) and such "cross-sex effects" can probably be negative (Anthes et al. 2010). 
of its sex functions. This clearly complicates interpretations compared to gonochorists, but it also presents some interesting targets for sexual conflict, including conflicts over which sex role the partner assumes and its sex allocation, as we discuss in the main sections below.

In contrast to the long history of research on interlocus sexual conflict, the possibility of intralocus sexual conflict in hermaphrodites has only been explored very recently (Abbott 2011; see also Arnqvist and Rowe 2005; Bedhomme et al. 2009). Consider a sexually antagonistic allele arising in a gonochorist. When expressed in (say) males, the allele benefits its bearer, whereas when expressed in females, the same allele is selected against. The ultimate fate of the allele in the population depends on how these benefits and costs balance out (and whether potential modifiers arise at other loci in the meantime) (Rice and Chippindale 2001). The situation in hermaphrodites is similar, in that one is still interested in the fate of a segregating allele that has opposing fitness effects on the carrier when expressed in sperm donors and sperm recipients, but in this case individuals (sequentially or simultaneously) express both sex functions, and so will often act as both sperm donor and sperm recipient within their own lifetime. Although we retain the familiar terminology for continuity, in a strict sense, this means that intralocus sexual conflict cannot exist, because the allele is not simply confined to individuals of one type (male/sperm donor) or another (female/sperm recipient). A useful alternative approach may be to think of such an allele simply in terms of antagonistic pleiotropy, with the opposing fitness effects in the male and female function representing a life-history trade-off, and with the accounting of those fitness effects playing out on a more immediate scale (i.e., within the lifetime of each and every individual in the population). However, this approach may be too simplistic for a number of reasons, which we consider in more detail in the main sections.

Any type of sex-specific selection must obey the frequency-dependent processes of the evolution of sex allocation, which differ between gonochorists and hermaphrodites in ways relevant to sexual conflict, as we outline next. Each zygote results from the fusion of a sperm and an egg, which, given anisogamy, contribute different amounts of resources to the embryo. Yet despite this initial asymmetry, the sexes make an equal genetic contribution (i.e., each offspring has exactly one father and one mother), and so exactly half of the fitness in the population results from male and female reproduction, respectively (the Fisher condition) (Houston and McNamara 2005). Under common assumptions of random mating (i.e., any sperm in the population has the same probability of fusing with any egg) and large population size (i.e., a gamete never encounters a related gamete), this predicts equal resource investment to male and female reproduction, as an unequal investment increases the fitness returns per unit of resource invested into the underrepresented sex function and frequency-dependent selection redresses the balance (Düsing 1884; Fisher 1930).

As a result of interactions between related mates and/or related gametes, however, deviations from these strong assumptions may arguably be the rule rather than the exception. Specifically, brothers sometimes compete for access to mates because of limited dispersal ("local mate competition") (Hamilton 1967; Charnov 1982), and related sperm (e.g., from within the same ejaculate) will often compete for access to eggs because of limited sperm mixing and/or internal fertilization ("local sperm competition”) (Schärer 2009; Schärer and Pen 2013). Such local competition will tend to limit returns on investment through the male function, which given the two routes to fitness in hermaphrodites will often favor a reallocation of resources toward the own female function and lead to an overall female-biased sex allocation, as reflected by both theoretical models and empirical data (Charnov 1982; Munday et al. 2006a; Schärer 2009). In contrast, males in gonochorists are more constrained, as they of course cannot directly reallocate to a female function, and so they instead appear to invest in other male routes to fitness, such as gaining more matings (see also Parker 2014). So although these common assumptions may also be broken in gonochorists, these seem less prone to exhibit biased sex allocation. Once sex allocation is biased toward one 
L. Schärer et al.

sex function, a higher fitness return per unit resource invested is obtained from the other sex function (i.e., half of the fitness is obtained with less than half of the resource investment), but the still-broken assumptions mean that this situation can be stable despite the fact the Fisher condition of course still holds. We believe that such biased sex allocation could contribute to preferred sex roles and other sources of sexual conflict between the mating partners, as we discuss specifically for sequential and simultaneous hermaphrodites in the respective main sections below (see also Schärer 2009).

In summary, we suggest that sexual conflict thinking can clearly be extended to hermaphrodites. However, a crucial difference is that the two sex functions simply do not map onto individuals in the way they do in gonochorists, likely complicating the picture for predicting the evolutionary dynamics of sexual conflict. The field would greatly benefit from theoretical work to fully understand the implications of whether and how the evolution of sexually antagonistic alleles is expected to differ between sexual systems, and we outline many relevant factors in the following sections. But in the meantime, we take the concepts we have developed here and apply them first to sequential and then to simultaneous hermaphrodites.

\section{SEXUAL CONFLICTS IN SEQUENTIAL HERMAPHRODITES}

\section{Sequential Hermaphrodites: The Basics}

Sequential hermaphroditism occurs when individuals can increase their reproductive value by changing sex. This requires that (1) the expected reproductive success is higher for one sex at one life stage and later becomes higher for the other sex, and (2) the fitness costs of changing sex (e.g., in terms of time out and/or physiological reorganization) do not exceed the expected fitness gains (potentially favoring simple reproductive systems in sex changers). Such changes in reproductive value are often linked to changes in body size and/or age (the size-advantage model) (Ghiselin 1969; Warner 1975; Munday et al. 2006a).
One scenario, as represented by anemonefishes, involves a local group inhabiting a spatially restricted habitat that forces group size to be very small. Here, a male cannot monopolize many females and thus male reproductive value depends only weakly on body size. In contrast, as is true for many fishes, female reproductive value increases strongly with body size. This scenario predicts protandrous sex change, in which individuals mature first as males and later change sex to become females. Another scenario, as represented by labroid fishes, involves a local group inhabiting a somewhat larger habitat that permits group size to reach half a dozen or more individuals. Here, a large dominant territorial male can monopolize several females and male reproductive value depends strongly on body size, and more so than for females. This scenario predicts protogynous sex change, in which individuals mature as females and later change sex to become males. In both scenarios, the sex exhibited by other individuals in the local group-and their sex change decisionsare major determinants of an individual's reproductive value (Munday et al. 2006a), so sex-specific selection will be highly frequencydependent.

\section{Intralocus Sexual Conflict}

A sequentially hermaphroditic individual could carry an allele that shows antagonistic pleiotropy for its male and female fitness (Schultz and Warner 1991; Abbott 2011). Imagine an allele in a protogynous hermaphrodite that increases an individual's aggression level at all life stages. Such an allele may make its carrier more successful when male by facilitating territorial defense, while having negative effects when female, for example, because aggression among females decreases fecundity. This scenario was recently suggested for the protogynous reef fish Parapercis cylindrica (Sprenger et al. 2012). Females that showed high aggression levels before sex change turned into more aggressive males. Independent evidence further suggested that high aggression levels may indeed be beneficial for males and detrimental for females in this sexual system (Sprenger et al. 2012, and 
references therein), which, assuming a genetic basis for the aggression level, might therefore be indicative of a sexually antagonistic allele (more specifically, a male-benefit/female-detriment allele). Insofar as the effect of such an allele is measured as lifetime fitness of its carrier (e.g., as the total number of offspring produced), we believe it can simply be seen as mediating a life history trade-off between the male and female function (before and after sex change).

As far as we know, there have been no systematic empirical or theoretical investigations of the evolutionary dynamics of sexually antagonistic alleles in sequential hermaphrodites, which might well be more complex than the simple trade-off scenario outlined above implies (see also Abbott 2011). One important consideration concerns the distribution of fitness across individuals in the population. In the protogynous bluehead wrasse, Thalassoma bifasciatum, mating success of territorial males varies considerably and can reach up to 100 females per day (mean \pm s.D. $=36 \pm 21)$, whereas females only mate about every 2 out of 3 days (Warner et al. 1995). So a male-benefit/female-detriment allele can potentially achieve a high fitness if it resides in a successful male (who may be successful as a male precisely because it carries this allele). Moreover, few individuals live long enough to eventually change sex (with mortality presumably involving a significant stochastic component) and the population sex ratio can be extremely biased (Warner and Hoffman 1980), which also means that very few individuals obtain most of the male fitness (old and large individuals can be extremely successful). Another consideration is how such a sexually antagonistic allele will affect the sex-specific and total fitness of the carrier's offspring bearing that allele (affecting the total number of grandchildren produced). Although such an allele may allow a father to produce many offspring, the above-mentioned skews and stochasticity may mean that none of its offspring will live to become a successful male that goes on to reap the same male-benefit effects, whereas all offspring may still suffer the female-detriment effects while being females. Also, the sex-specific effects of a spreading sexually antagonistic allele are likely to be strongly affected by frequencydependent selection (Abbott 2011).

One way that a sexually antagonistic allele can increase the probability of reaping the benefits and avoiding the costs of being expressed in a specific sex would be to either (1) influence, or (2) become associated with the sex change decision (Arnqvist and Rowe 2005; Abbott 2011). In the reef fish example above, the former might occur if a high aggression level were achieved by a high titer of a circulating hormone that also causes an earlier sex change (i.e., an earlier sex change could be seen as a pleiotropic effect of a trait for high aggression). The latter could result from linkage disequilibrium, in which alleles for early sex change become statistically associated with male-benefit alleles (i.e., alleles for early sex change may tend to be inherited together with male-benefit alleles) or, more permanently, from actual physical linkage of such alleles in the genome, both resulting in a genetic correlation. Relatively little is currently known about the genetics of sex change decisions in sequential hermaphrodites (but see Hodgkin and Barnes 1991), but it is clear that these decisions show a high degree of plasticity in many species (Munday et al. 2006a; see also next section), so it is not evident how easily sexually antagonistic alleles could become linked to the change decisions. Interestingly, any allele that advances the timing of sex change in a protogynous hermaphrodite will likely make its carrier a more successful sperm donor and a less successful sperm recipient, and so could itself be viewed as a sexually antagonistic allele. Thus, we can rephrase the idea of this paragraph to say that male-benefit/female-detriment alleles may benefit from becoming evolutionarily associated with other male-benefit/female-detriment alleles, leading to sex-role specialization.

\section{Interlocus Sexual Conflict}

As mentioned above, sex change decisions can be highly phenotypically plastic, and it is therefore interesting to consider what kinds of constraints might restrict an individual's freedom to decide whether and when to change sex. For example, in a protogynous hermaphrodite, 
L. Schärer et al.

the fitness of a large territorial male depends strongly on the sex change decisions of the other individuals in its local group, for two separate reasons. When a female decides to change sex, the territorial male potentially (1) loses a female mate and any future fitness that might have derived from mating with her, and (2) gains a male competitor that may start to compete for matings (or fertilizations) in the local group. It therefore appears plausible that there could be sexual conflicts over the occurrence and timing of sex change between the territorial male and the resident females, and that a male may actively try to prevent the females from changing sex. This could involve some form of social control of sex change, which is a widespread (although by no means universal) phenomenon in sequential hermaphrodites (e.g., Robertson 1972; Warner and Swearer 1991; Collin et al. 2005; reviewed in Munday et al. 2006a), and often involves stunning phenotypic plasticity. In several species, experimental removal of the territorial male leads to the largest female taking over the dominant role within the group very rapidly, sometimes even within a few minutes (e.g., Warner and Swearer 1991), although it takes several days or even weeks for them to become functional males (Warner and Swearer 1991; Sprenger et al. 2012).

Social control of sex change could result from at least two different scenarios. In the first, a female essentially evaluates the probability of increasing her reproductive value by changing sex, and concludes that she is better off remaining an active female, and waiting for a territory to become available. In this case, we can view the female's poor prospects for changing sex to be the result of male-male competition in that, by investing in territoriality, the territorial male leaves no room for a prospective male to gain more fitness than it could currently do as a female. This seems not to involve sexual conflict, at least in the classical sense, as the conflict involves male-male competition and the individual's interests are harmed only indirectly (by denying it the potential benefits of changing sex). In the second scenario, the female concludes that changing sex would indeed be the preferred option to maximize her reproductive value (e.g., because reduced spending on making eggs could lead to a growth spurt and increase her chances of eventually becoming a successful male; cf. Warner 1984), but she is actively prevented from executing that choice by the territorial male, possibly by aggression-induced stress hormones that physiologically prevent sex change (cf. Marsh-Hunkin et al. 2013). Such aggression might cause direct fitness costs to the female, reducing her egg production below the level she would have achieved without it, which one would clearly view as sexual conflict. A third, possibly intermediate, scenario could result if the territorial male, by directing aggression toward male intruders, somehow causes collateral harm to females. An interesting study that could be seen in this context is that of Warner et al. (1995), who showed that the most successful territorial males release so few sperm that they provide the lowest fertilization rates to their females, presumably because territorial defense is so costly that they need to economize on how much sperm they can produce and allocate to each female.

As a result of hermaphrodites having two routes to fitness (Fig. 1), it may be difficult to determine empirically whether sexual conflict affects the male or female fitness of the partner (who is ultimately trying to optimize total fitness), thus making it difficult to decide which of the above scenarios represents "sexual conflict." One could argue that in all three scenarios it is the same other individual whose (male, female, or both) genetic interests are harmed, thus making it somewhat artificial to consider certain scenarios as involving sexual conflict and others not. Ultimately, this reflects the difficulty of mapping the notions of "males" and "females" onto sequential hermaphrodites (because all individuals can be both). Nevertheless, we believe that the last two scenarios could readily be thought of as interlocus sexual conflict, predicting sexually antagonistic coevolution between a (male-benefit inducing) male persistence trait (e.g., aggression) and a (female-detriment avoiding) female resistance or tolerance trait (e.g., insensitivity to the stress hormone). We are not aware that this possibility has been explored, either empirically or theoretically. The 
first scenario might also lead to similar coevolutionary dynamics, but here driven by malemale competition between male-benefit inducing alleles and male-detriment avoiding alleles (e.g., small males trying to mimic females, as observed in some diandric hermaphrodites) (Munday et al. 2006b).

\section{SEXUAL CONFLICTS IN SIMULTANEOUS HERMAPHRODITES}

\section{Simultaneous Hermaphrodites: The Basics}

Simultaneous hermaphroditism could be favored (1) by facilitating reproductive assurance when individuals (or their gametes) risk failed reproduction for lack of encountering partners (Darwin 1876; Tomlinson 1966; Ghiselin 1969), (2) if the male and female reproductive functions do not (strongly) trade off, because they have nonoverlapping resource requirements or can share costs (Charnov et al. 1976; Heath 1979), or (3) if the investment to a sex function shows diminishing fitness returns (e.g., because of low mobility) (Ghiselin 1969), restricted "mating group size" (Charnov 1980), and/or local sperm competition (Schärer 2009; Schärer and Pen 2013), thus favoring reallocation of remaining reproductive resources to the other sex function. The balance of evidence suggests that all these factors may play some role, but the last is likely the most important, at least in animals (reviewed in Schärer 2009).

The best-studied determinant of sex allocation in simultaneous hermaphrodites is the mating group size, which affects the strength of male-male competition in a local group. If mating group size is very small, then little is gained from male investment beyond some minimum needed to ensure full fertility because sperm from a single ejaculate largely compete among themselves for fertilization (termed "local sperm competition” in Schärer 2009) and more is gained from reallocating resources to the female function, resulting in a stable female-biased sex allocation. As mating group size increases, however, success in sperm competition (between sperm from different donors) (Parker 1970) becomes increasingly important to determining fitness through the male sex function, favoring a greater male investment and thus a more even sex allocation. Of course, mating group size can vary in space and time, which in many species has favored the ability to plastically adjust sex allocation to the prevailing (social) conditions (reviewed in Schärer 2009). Such sex allocation adjustment mechanisms could potentially be manipulated by mating partners and are therefore a putative target of sexual conflict in simultaneous hermaphrodites (Charnov 1979; Michiels 1998; Schärer 2009; Schärer and Janicke 2009; see also below).

\section{Intralocus Sexual Conflict}

Most work on simultaneous hermaphrodites concerns interlocus sexual conflict (see below), and with respect to intralocus sexual conflict, there are many parallels with sequential hermaphrodites, so this section will be brief. In simultaneous hermaphrodites, male and female fitness is probably also often distributed differently over individuals in a population, and although individuals generally exhibit both sex functions simultaneously, the emphasis often shifts with size (or age), leading to size-dependent sex allocation (Klinkhamer and de Jong 1997; Schärer et al. 2001; Schärer 2009). So here again we can expect linkage to arise between sexually antagonistic alleles and alleles that influence sex allocation (and note here that the latter can again be viewed as largely equivalent to the former). Although there is now ample evidence that sex allocation can be extremely plastic in many simultaneous hermaphrodites (Schärer 2009), there is also some evidence for standing genetic variation in sex allocation (e.g., Hughes 1989; Yund et al. 1997; S Ramm and L Schärer, unpubl.), thus such linkage is clearly possible. Moreover, many traits in simultaneous hermaphrodites may evolve as a result of interlocus sexual conflict and antagonistic coevolution (see below), so there could be many sexually antagonistic alleles with asymmetric fitness effects. For example, a novel seminal fluid (male persistence) allele could have a weak negative (pleiotropic) effect on the female function of its carrier (e.g., 
L. Schärer et al.

because of general toxicity or negative effects during selfing), which is to say that an allele that arises in the context of interlocus sexual conflict (aimed at manipulating the mating partner) can simultaneously generate intralocus sexual conflict (by imposing harm on the carrier's own female function). Similar effects could result from any allele involved in sexually antagonistic coevolution, and most if not all such alleles likely involve some degree of intralocus sexual conflict, if only because investment in the relevant trait draws resources from a common resource pool (and thus likely comes at some cost to the individual, including its female sex function). In the remaining subsections, we focus on different aspects of interlocus sexual conflict.

\section{Premating Conflicts: The Battleground}

Sexual conflicts over mating ("mating conflicts") in simultaneous hermaphrodites relate to asymmetries between acting as a sperm donor or sperm recipient in the benefits of mating versus its costs (Table 1) and manifest themselves in unique conflicts over mating interactions (Charnov 1979; Michiels 1998). The evolutionary battleground for such mating conflicts can be visualized as a matrix of compatible and incompatible behavioral interactions, which are defined by the interest of two individuals to be a sperm donor, a sperm recipient, or both (Fig. 2A) (Michiels 1998). Mating conflicts occur whenever the interacting individuals want to adopt incompatible sex roles. We
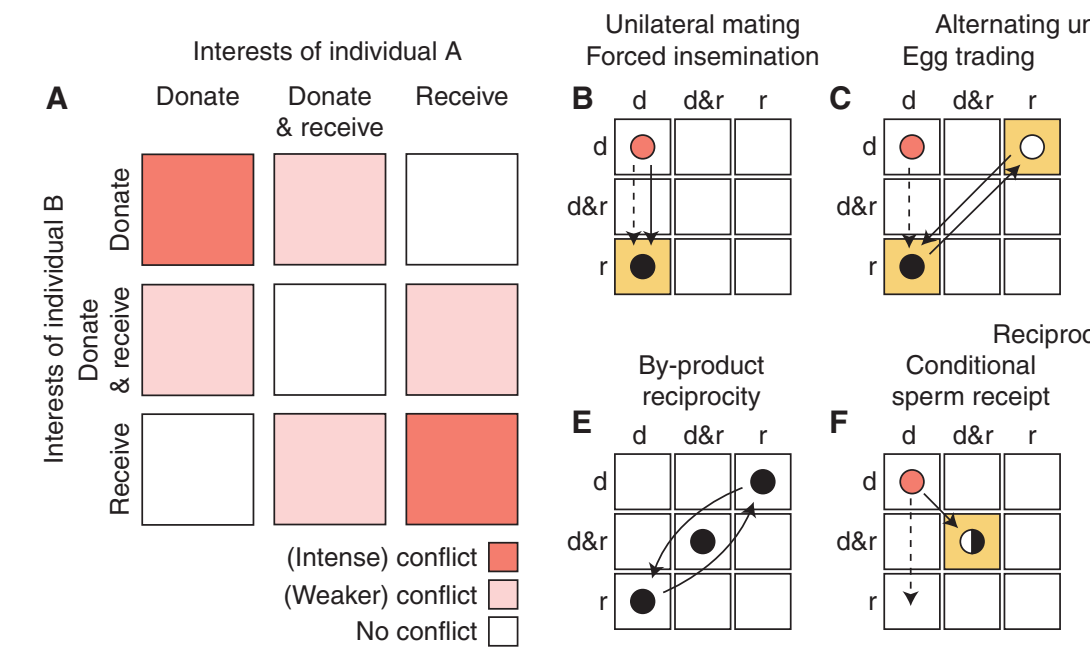

lateral mating Sperm trading
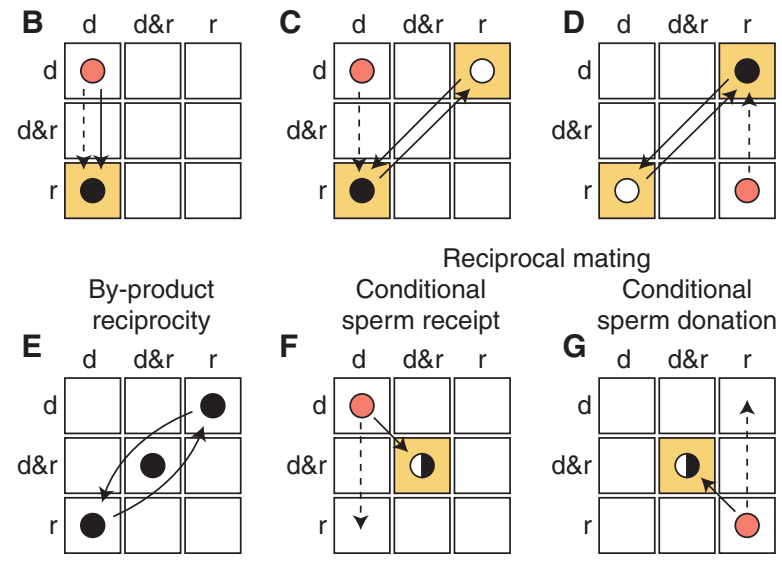

Figure 2. Evolutionary battleground of mating conflicts in simultaneous hermaphrodites (modified from Michiels 1998) and some potential routes to resolution. (A) Mating conflicts between individuals A and B can arise from incompatible interests to donate and/or receive sperm. $(B-G)$ The routes to resolution of mating conflicts over incompatible interests (i.e., donate sperm, $d$; receive sperm, $r$; or both donate and receive sperm, d\&r) encompass the following possibilities (viewed from individual A's perspective): forced unilateral insemination $(B)$; gamete trading with alternating unilateral matings, namely, egg trading $(C)$ or sperm trading $(D)$; by-product reciprocity $(E)$; and gamete trading during reciprocal matings, namely, conditional sperm receipt $(F)$ or conditional sperm donation $(G)$. Red squares in $A$ and the circles in $B-G$ characterize the conflict over mating. Dashed arrows indicate the optimal behavioral outcome for individual A and solid arrows denote the realized behavioral outcome for a given resolution of mating conflict. Yellow squares in $B-$ $G$ point to the type of interaction by which the conflict is resolved reflecting benefits (black circles) and costs (open circles) for individual A. Note that by-product reciprocity $(E)$ does not actually involve conflict (no yellow squares), but it looks superficially similar to cases that do and so is included here for comparison. Specifically, the curved arrows connecting the upper-right and bottom-left squares in $E$ are similar to the cases of alternating unilateral matings in $C$ and $D$, and the central squares in $E$ are similar to the cases of reciprocal matings in $F$ and $G$. 
first review the theoretical framework and empirical evidence for sex-role preferences, as they represent a key assumption for mating conflicts to arise, and then discuss hypotheses developed for, and evidence bearing on, the resolution of such conflicts.

\section{Premating Conflicts: Sex-Role Preferences}

The theoretical foundations of sex-role preferences date back to Bateman (1948), who compared the fitness benefits of mating between male and female fruit flies. The study revealed a "greater dependence of males for their fertility on frequency of insemination" (Fig. 3) (later coined "Bateman's principle" by Charnov 1979) and suggested this pattern is "an almost universal attribute of sexual reproduction" in both an-

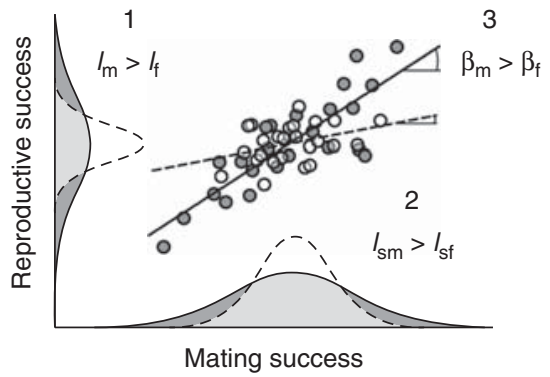

Figure 3. Schematic illustration of Bateman's three principles as proposed by Arnold (1994). The sex that experiences the stronger sexual selection (usually the male or sperm donor) is predicted to show (1) a higher relativized variance in reproductive success (also called opportunity for selection, $I$ ), (2) a higher relativized variance in mating success (also called opportunity for sexual selection, $I_{\mathrm{s}}$ ), and (3) a steeper Bateman gradient (i.e., the slope of an ordinary least squares regression of reproductive success on mating success; also called sexual selection gradient, $\beta$; Arnold and Duvall 1994). The graph shows arbitrary data for the male $(m$; gray circles and density curves; solid line) and female ( $f$; open circles and density curves; dashed line) sex. Note that in simultaneous hermaphrodites, the male and female estimates can be obtained from the same individual, so that reproductive success of one sex function can be regressed on mating success of the other sex function. The slopes of such regressions denote "cross-sex effects" that are indicative of trade-offs in sex allocation or sexual antagonism. (Adapted from Anthes et al. 2010.) imals and plants (Bateman 1948), thus presumably including hermaphrodites. Three decades later, Charnov (1979) explored the hypothesis that Bateman's principle also applies to simultaneous hermaphrodites, arguing that hermaphroditic individuals may "copulate not so much to gain sperm to fertilize eggs as to give sperm away," which he expected to result in an overall preference for the male role and frequent conflicts of interest between mating partners (Fig. 2A, upper-left panel of the matrix).

Empirical data in terms of so-called Bateman gradients (Fig. 3) are still limited, but they tend to support Charnov's contention. In the freshwater gastropods, Biomphalaria glabrata and Physa acuta, the male gradients are steeper than the female gradients (Anthes et al. 2010; Pélissié et al. 2012). It is important to spell out why this may often be the case, particularly in species with internal fertilization and sperm storage. The shallow female gradient mainly results from what happens after the first mating in the female role, at which point the female function may have sufficient stored sperm to maintain fertility (i.e., a single mating can potentially switch the female function from infertile to fully fertile). So if one counts the number of "profitable" matings that can be achieved through the male and female function, there are clearly more to be had through the male function (i.e., the male function may obtain some fitness each time the individual mates as a male). The overall male sex-role preference could then simply be seen as a sampling effect. A randomly sampled individual in the population will normally gain more from mating next as a male, because it likely has mated as a female already. The empirically observed Bateman gradients thus probably mean that these snails show a male sex-role preference (Anthes et al. 2010; Pélissié et al. 2012), and two studies on sea slugs, in which only the female function was examined, even suggested costs for high female mating rates (Sprenger et al. 2008; Lange et al. 2012).

This perspective suggests that sex-role preferences need not be fixed, as emphasized by the "gender-ratio hypothesis" (Anthes et al. 2006b). Even if one sex function can usually benefit more from an additional mating, the actual fitness 
L. Schärer et al.

gains from mating as a male or female during any particular encounter will depend on a range of factors, notably the mating history (and thus sperm reserves as both donor and recipient) (e.g., Wethington and Dillon 1996; Anthes et al. 2006a; Ludwig and Walsh 2008), as well as other life-history traits, such as fecundity, survival, and sex allocation of the sperm donor and/or the recipient (e.g., DeWitt 1996; Gianguzza et al. 2004; Janicke and Schärer 2009b; Dillen et al. 2010). This provides a more flexible framework for thinking about variation in sex-role preferences (Anthes et al. 2006b), and all that is required for conflict is that at least some encounters lead to incompatible mating interests.

Measuring male and female Bateman gradients is clearly a promising approach to predict sex-role preferences and the intensity of the resulting mating conflicts (expressed as the slope difference) (see also Anthes et al. 2010). However, Bateman gradients only quantify the average fitness returns an individual can expect from an additional mating in a given sex role, whereas they ignore the costs that have accrued to obtain that fitness (Jennions and Kokko 2010; Kokko et al. 2012). These costs might also be affected as a result of sex allocation biases (Schärer 2009). Specifically, a female-biased sex allocation will, given the Fisher condition, on average lead to a higher fitness return per unit resource investment to the male sex function. Investing one unit of resource into mating in the male role could therefore potentially be more profitable than investing the same amount in the female role. Given that a female-biased sex allocation is predicted under many conditions and actually observed in many species (reviewed in Schärer 2009; Schärer and Pen 2013), this could potentially further contribute to a preference for the male sex role among simultaneous hermaphrodites.

Alternative ideas about sex-role preferences instead predict a female preference. For example, many simultaneous hermaphrodites possess specific organs to digest sperm and/or other ejaculate components (reviewed in Baur 1998; Michiels 1998; Nakadera and Koene 2013) and so direct (nongenetic) benefits from mating in the female role could potentially result from ejaculate digestion, which might generate a female sex-role preference. However, to our knowledge, evidence that the digestion of ejaculates is actually energetically beneficial to the recipient is still lacking (see Postmating Conflicts sections below). Other direct benefits of multiple mating, such as nuptial gifts or paternal care, are presumably also of minor importance as the former, to our knowledge, do not exist (other than possibly via ejaculates; see below) and the latter is rare in simultaneous hermaphrodites (but see Sella and Ramella 1999).

An additional hypothesis posits that a critical factor for sex-role preferences is the risk of one's gametes remaining unfertilized. Specifically, the "gamete trading hypothesis" (Leonard and Lukowiak 1984, 1985; Leonard 1990) assumes that (1) in internally fertilizing hermaphrodites, it is the female role that has more control over the fate of the invested gametes and that this role may therefore be preferred (although there is accumulating evidence that sperm donors often retain at least some control over the fate of their gametes; see also the Postmating Conflicts sections below). Moreover, the hypothesis assumes that (2) in externally fertilizing species, the male role should be preferred as eggs are often released before sperm, which carries the risk they will not be fertilized. However, this implies that a sperm donor would decline to fertilize, at presumably small cost, the (costly) eggs spawned by the partner, even after having invested in precopulatory interactions, which seems implausible (and would probably have to be seen as spiteful behavior). And finally, the gamete trading hypothesis is based on the assumption that the low-risk strategy has a higher mean fitness, which cannot hold given the Fisher condition, as previously pointed out by Greeff and Michiels (1999).

Overall, the currently available empirical evidence suggests a preference to copulate in the male sex role to be generally more likely, but the conditions thought to favor a female sex-role preference remain largely unexplored. Continued efforts to measure the strength of sexual selection in a range of different hermaphroditic systems (Lorenzi and Sella 2008; Anthes et al. 
2010; Pélissié et al. 2012) will likely permit a better understanding of Bateman's three principles (Fig. 3) and enable these and some additional proposed hypotheses for sex-role preferences to be properly evaluated (e.g., Crowley et al. 1998; Leonard 1999; reviewed in Leonard 2005, 2006).

\section{Premating Conflicts: Routes to Resolution}

Mating conflicts in simultaneous hermaphrodites appear to be resolved in various ways, ranging from the selfish imposition of the nonpreferred role on the mating partner to putatively cooperative mating interactions (Fig. $2 \mathrm{~B}-\mathrm{G})$. A common approach to predict behavioral strategies arising from conflicts over preferred sex roles is game theory. For example, Axelrod and Hamilton (1981) used an iterated Prisoner's Dilemma to model the intriguing mating behavior of a reef fish, the black hamlet Hypoplectrus nigricans-first observed and termed "egg trading" by Fischer (1980)_and they suggested that it involves conditional reciprocity via a tit-for-tat strategy, thus potentially resolving mating conflicts arising from a shared interest to donate sperm in a cooperative way (see also Fischer 1988; Leonard 1990; Crowley et al. 1998). However, we discuss egg trading in some detail below and conclude that the payoff matrices of these models probably do not properly capture the biology of the black hamlet. This example clearly illustrates the need for empirical data that enable the possible strategies to be properly defined and thereby parameterize the payoff matrix of a given mating interaction to predict how mating conflicts could be resolved. This requires not just extensive knowledge about the reproductive biology of a given system, but also about how environmental conditions (such as density and predation risk) may alter the payoffs for reciprocation and defection (Crowley and Hart 2007; Hart et al. 2010). Ultimately, one probably needs manipulative experiments to assess the costs and benefits of the different strategies, to corroborate the importance of particular traits and mating states, and to substantiate claims of strategies involving conditionality (see, e.g., Anthes et al. 2005).
To illustrate the great diversity of behavioral adaptations putatively arising from mating conflicts we start with an apparently simple form of conflict resolution-forced unilateral insemination (Fig. 2B) — which seems to be associated with high costs of sperm receipt, making cooperative behaviors presumably unlikely to evolve. Such overt conflict characterizes the mating behavior of the marine polyclad flatworm Pseudoceros bifurcus, in which both interacting individuals attempt to inject sperm hypodermically into their opponent, while trying to avoid being stabbed themselves, as the latter incurs costs of injury (Michiels and Newman 1998; Arnqvist and Rowe 2005). This so-called "penis-fencing" supposedly originates from a higher benefit of sperm donation, although experimental evidence for a male preference to copulate is also still lacking for this species (for other examples of forced unilateral matings, see Michiels 1998, and references therein).

Unilateral matings may also occur consensually when the mating interests of both partners are compatible. For example, many freshwater gastropods mate unilaterally without it resembling the hit-and-run strategy outlined before for flatworms. In such systems, the mating status and thus the amount of available allosperm (i.e., received sperm to fertilize own eggs) and autosperm (i.e., produced sperm and/or seminal fluid for donation) might predict a preference for playing the male or female role at any one time (Wethington and Dillon 1996; Koene and ter Maat 2005), even in the presence of an overall sex-role preference (see "gender-ratio hypothesis" above) (Anthes et al. 2006b). In these systems, occasional conflicts arising from a shared male preference might simply be resolved by an evasive behavior of the would-be female-acting snail (DeWitt 1991; Wethington and Dillon 1996).

Several unilaterally copulating simultaneous hermaphrodites exhibit pronounced sexrole alternation when mating, which is considered one of the best examples for cooperative behavior via reciprocity (Dugatkin 1997). However, for many of the studied systems it remains unclear whether the observed alternation of sex roles actually involves conditionality (i.e., actual 
L. Schärer et al.

trading of eggs or sperm; see Fig. 2C and 2D, respectively), or whether it is just a side effect of a mutual willingness (1) to copulate in both sex roles, or (2) to copulate in one sex role while not objecting to mating in the other (herein called "by-product reciprocity," curved arrows connecting the upper-right and bottom-left panels in Fig. 2E) (Michiels 1998; Anthes and Michiels 2005; Facon et al. 2008).

As briefly outlined above, alternating unilateral exchange of gametes was first described by Fischer (1980), who, based on behavioral observations, suggested that in the black hamlet (and some other serranid reef fishes), a conflict over mating in the male role is resolved by "egg trading." Egg trading involves the parceling of the clutch into small subunits, which are then conditionally exchanged by alternating between adopting the preferred sex role, sperm donation, and the nonpreferred sex role, egg donation (or sperm receipt) (Fig. 2C) (Fischer 1980, 1984, 1987; Pressley 1981; Petersen 1995, 2006). Early approaches modeled this as a two-player game with no option to desert and mate with another individual (Axelrod and Hamilton 1981; Fischer 1988; Leonard 1990). However, Connor (1992) showed that incorporating costs of desertion (e.g., for mate searching or higher predation risk) and allowing the size of the egg parcels to be adjusted may in fact make it more profitable to offer the next batch of eggs to the current partner than to leave in search of other mating opportunities. Moreover, Petersen (2006) stressed that the model assumption of equivalent players and symmetric payoffs are often violated and that we therefore urgently need field estimates of parcel size in egg-trading fish. Similarly, egg trading has been proposed to occur during mating interactions of externally fertilizing polychaetes of the genus Ophryotrocha, which also show serial alternation of sex roles (Sella 1985, 1988; Sella et al. 1997; Sella and Lorenzi 2000). However, for both of these putative egg-trading systems, firm experimental corroboration of conditionality (e.g., by showing punishment of experimental cheaters) is still lacking and an overall preference for mating in the male sex function has, so far, only been assumed rather than tested.
Another form of alternating unilateral exchange of gametes, sperm trading (Fig. 2D), was suggested to occur in sea slugs (Leonard and Lukowiak 1984, 1991; Karlsson and Haase 2002; Michiels et al. 2003; Anthes et al. 2005; but see Anthes and Michiels 2005). However, in most of these empirical studies, sperm trading was only inferred from the alternating unilateral exchange of sperm, which might in theory also arise as a by-product of a shared preference to donate with no objection to receive sperm (see Fig. 2E) (Michiels 1998; Puurtinen and Kaitala 2002; Schärer and Pen 2013). Convincing support for conditional sperm trading comes from just a single study. Anthes et al. (2005) experimentally manipulated the ability to donate sperm in the sea slug Chelidonura hirundinina, showing that individuals are reluctant to continue mating with such a nonreciprocating partner. Nevertheless, this observed reluctance could still be interpreted as a rejection of nonpreferred mating partners, rather than a punishment of cheaters, if sperm donation serves as a sexual signal indicating the viability of the donor, as hypothesized by Landolfa (2002).

Initially, sperm trading was proposed to occur in internally fertilizing hermaphrodites with an overall preference to copulate in the female sex function based on the "gamete-trading hypothesis" (see previous subsection; Leonard and Lukowiak 1984). In contrast, it has also been argued that sperm trading can be associated with a male sex-role preference even if ejaculates are costly for the donor and provide an energetic benefit to the receiver (Greeff and Michiels 1999). According to this so-called "opportunistic male hypothesis" sperm donors trade their nutrient-rich ejaculates to get access to the eggs of their opponents (Michiels et al. 2003). Here, the ejaculate may function as a nuptial gift and potentially as paternal investment in addition to its usual function in mediating sperm donation to fertilize eggs (Yamaguchi et al. 2012), as has been proposed for many gonochorists (e.g., Vahed 1998). We, however, see problems with this nuptial gift argument, namely, that there must be a considerable energy conversion loss when sperm is first produced and then digested (see also Leonard 2005) and 
that ( just as with nuptial gifts in general) there is no guarantee that the partner will actually use the received energy to make eggs (or that the already existing eggs would preferentially be fertilized by that donor). Both these caveats mean that fitness could usually be obtained much more reliably by instead investing the resources into the own female function. Indeed, when considering a commonly observed energy transfer efficiency between trophic levels of 10\% (Pauly and Christensen 1995), rather than the probably unrealistically high value of $50 \%$ used by Yamaguchi et al. (2012), then the increase in male allocation compared to their model without a nuptial gift effect is indeed minute $(<1 \%-2 \%$ in most cases $)$. And finally, the opportunistic male hypothesis relies on the thus far unproven assumption that sperm digestion actually yields a net resource benefit to the sperm recipient (see the Postmating Conflicts sections below).

Finally, many simultaneous hermaphrodites such as flatworms, annelids, and gastropods show reciprocal mating by donating and receiving sperm at the same time (e.g., Vreys and Michiels 1997; Baur et al. 1998; Michiels and Streng 1998; Michiels and Bakovski 2000; Schärer et al. 2004; Jordaens et al. 2005; Domínguez and Velando 2013), which may or may not result from a conflict over the preferred sex role (see also Puurtinen and Kaitala 2002). In practice, it will usually be difficult to distinguish conditional sperm receipt (Fig. 2F) and conditional sperm donation (Fig. 2G) from by-product reciprocity (Fig. 2E) in reciprocally mating hermaphrodites (Anthes and Michiels 2005), unless sperm transfer can be measured and experimentally manipulated simultaneously in a given copulation, clearly a very challenging task.

To conclude, mating conflicts in simultaneous hermaphrodites are apparently resolved in ways which seem to reflect, at least partially, the proposed asymmetries in the net benefit of acting as a sperm donor and recipient. However, even for well-studied systems we usually still lack detailed information on the payoffs of the observed behavioral strategies, which are needed to fully understand how the mating conflict is resolved. Consequently, it is too early to spec- ulate on the relative incidence of the different types of conflict resolution.

\section{Postmating Conflicts: The Battleground}

Even after mating, there remains scope for conflicts of interest between the sperm donor and sperm recipient. Many of these are similar to the phenomena occurring between males and females in gonochorists. Often, however, we expect postmating conflicts to be especially relevant in simultaneous hermaphrodites, for two main reasons: (1) because of the apparent scarcity of overt premating sexually selected traits and the frequent willingness of both partners to mate (or their inability to avoid doing so), meaning we can expect a general shift in sexual selection from the pre- to the postmating arena, and (2) because simultaneous hermaphroditism creates unique targets for sexual conflict, most notably via manipulating also the male sex function and overall sex allocation of the mating partner (Charnov 1979; Michiels 1998; Arnqvist and Rowe 2005; Schärer 2009; Schärer and Janicke 2009). Below, we examine postmating conflicts first from the perspective of the sperm donor attempting to manipulate the sperm recipient and then from the perspective of the sperm recipient attempting to retain or regain control of events occurring after mating.

\section{Postmating Conflicts: Interests of the Sperm} Donor

Just as for males in gonochorists (see Edward et al. 2014), several adaptations in simultaneous hermaphrodites likely function to maximize the fertilization success of sperm donors under sperm competition, in a manner that may not be in the recipient's interest. Relevant traits include the number (e.g., Velando et al. 2008) and morphology (e.g., Schärer et al. 2011) of sperm transferred; mechanisms for the efficient transfer of sperm (e.g., Janicke and Schärer 2009a), or for physical displacement of previously deposited sperm (a proposed function of the "disposable" penis of the sea slug Chromodoris reticulata, Sekizawa et al. 2013); suppression of remating by sperm recipients (see below); and 
L. Schärer et al.

maximization of the amount of transferred sperm that are retained in storage and used for fertilization (e.g., Landolfa et al. 2001; Rogers and Chase 2002; Chase and Blanchard 2006; Dillen et al. 2009; Garefalaki et al. 2010; Kimura and Chiba 2013). In the following, we discuss first one especially relevant target of manipulation in simultaneous hermaphrodites, namely, aspects of the recipient's sex allocation (Charnov 1979; Michiels 1998), and then consider the various ways in which manipulative substances can be transferred from the donor to the recipient.

Two main types of sex allocation manipulation can be envisaged (Schärer 2009, 2014; Schärer and Janicke 2009). First, the sperm donor could directly affect the female function of the sperm recipient in whatever manner maximizes its reproductive success, and this is essentially analogous to a male manipulating a female in gonochorists. Alternatively, the sperm donor could indirectly boost the mating partner's female function by attacking that individual's male function, assuming that this actually leads to a reallocation of resources to the recipient's female sex function (i.e., assuming plasticity and a sex allocation trade-off ), and further assuming that the sperm donor itself gains some advantage from this relative to its competitors, which cannot just be assumed (Schärer 2014). Manipulating the partner's sex allocation should therefore be particularly advantageous in species with low levels of multiple mating, in which manipulation would likely yield benefits exclusively or mainly to the manipulating individual. In this context, a second potential advantage of attacking the recipient's male function may also be to boost the donor's paternity share, as an impeded male function may prevent the recipient from remating in either sex role, which might lower the level of sperm competition experienced by the manipulating focal (see Schärer 2014).

A major route through which manipulative substances (collectively termed "allohormones") (Koene and Chase 1998; Koene and ter Maat 2001) can be transferred from donor to the recipient is in the ejaculate (Zizzari et al. 2014). Seminal-fluid-mediated effects are in- creasingly recognized as a common source of sexual conflict (see Sirot et al. 2014), also in simultaneous hermaphrodites, as originally predicted by Charnov (1979). For example, seminal fluid investment (as indicated by variation in prostate gland size) covaries with female reproductive tract morphology among opisthobranch sea slugs in a manner consistent with sexually antagonistic coevolution (Anthes et al. 2008). Moreover, the receipt of possibly manipulative seminal fluid substances could explain why Macrostomum lignano flatworms mated to virgin partners (that have more seminal fluid in storage to transfer) are less likely to perform the postcopulatory "suck" behavior, hypothesized to function in influencing the fate of received ejaculate components (MarieOrleach et al. 2013).

By far the best-studied hermaphroditic system with respect to seminal fluid function is the pond snail Lymnaea stagnalis, in which several seminal fluid components have recently been identified that influence the partner's reproductive behavior and/or resource allocation. One protein called LyAcp10 (also called ovipostatin) suppresses short-term egg production (Koene et al. 2010), by reducing the number of eggs produced (see also Van Duivenboden et al. 1985; Koene et al. 2006, 2009), while apparently increasing the biomass associated with each egg (Hoffer et al. 2012), although precisely what advantage the sperm donor may gain from this remains unclear. Moreover, an intriguing study by Nakadera et al. (2014) recently found an even more surprising effect, namely, that two proteins (LyAcp5 and LyAcp8b) significantly decrease the amount of sperm a recipient transfers in its next mating (note that LyAcp10 may actually have a similar effect). These studies are clearly highly relevant in the context of the sex allocation manipulations discussed above, but given that they focused on measuring short-term effects on female and male reproduction, respectively, it is currently difficult to interpret these findings. Future studies should aim at simultaneously measuring effects on both sexes, preferably over longer time periods (Schärer 2014).

A second route through which manipulative substances can be transferred from sperm 
donor to recipient, and one that appears especially common in simultaneous hermaphrodites (Lange et al. 2013a), is via accessory structures that appear to have evolved specifically for this purpose (Zizzari et al. 2014). Striking adaptations in this context are the so-called "love darts" of various land snails (reviewed in Koene 2006; Chase 2007). Experimental evidence in Cornu aspersum (formerly Helix aspersa) indicates that these sharp, calcareous structures-injected into the mating partner's body before copulation-transfer bioactive substances that cause muscular contractions of the female reproductive tract (Koene and Chase 1998), promoting sperm storage (Rogers and Chase 2001), and enhancing paternity success (Landolfa et al. 2001; Rogers and Chase 2002; Chase and Blanchard 2006). In contrast, the mucus transferred via the love dart of the snail Euhadra quaesita appears to suppress remating in recipient individuals (Kimura et al. 2013), suggesting that dart shooting can serve multiple functions (see also Adamo and Chase 1990). Love darts may be counter to sperm recipient's interests for two reasons: by (1) wounding them (Baur 1998, but see Chase and Vaga 2006), and (2) manipulating their reproductive physiology or behavior. As might then be expected from the resulting interlocus sexual conflicts, love darts are highly variable across species (Koene and Schulenburg 2005; Koene et al. 2013) and display signatures of antagonistic coevolution and counteradaptation by sperm recipients in the form of modified reproductive organ morphologies (Koene and Schulenburg 2005; see also Davison et al. 2005; Beese et al. 2009; Sauer and Hausdorf 2009). Similar functions may be performed by the copulatory setae of earthworms (Koene et al. 2002, 2005; König et al. 2006) and devices such as the stylet-like penis appendage found in Siphopteron sea slugs (Anthes and Michiels 2007; Lange et al. 2014) and the penial gland that is everted following external sperm exchange in Deroceras land slugs (Reise 2007; Reise et al. 2007; Benke et al. 2010; for a recent review of "traumatic secretion transfer," see also Beese et al. 2009 and Lange et al. 2013a). In all of these cases, however, the exact costs and benefits to donor and recipient be- cause of either wounding or receipt of a specific (manipulative) substance under naturalistic conditions remain to be determined.

Irrespective of their method of delivery, allohormones in simultaneous hermaphrodites have been predicted to differ from those in gonochorists. In the former, both male and female substances are expressed in all individuals, which might permit donors to more easily "borrow" their own female substances to manipulate their mating partners, whereas in the latter, such substances will usually have sex-specific expression, which might require more drastic changes in expression (Koene 2005). Too few allohormones have so far been identified to permit a meaningful comparison between sexual systems, but even in hermaphrodites such female substances are normally expressed at different levels in different tissues and would still presumably need to be expressed more highly in novel tissues before they could be coopted by the male function. So the differences between sexual systems may not be so profound in this respect.

\section{Postmating Conflicts: Interests of the Sperm Recipient}

As we have seen, individual simultaneous hermaphrodites may often either agree to mate reciprocally or be unable to avoid mating in the role of sperm recipient. This means that they will typically receive many ejaculates. Receiving large amounts of sperm and/or other ejaculate components could be problematic for several reasons, some of which can be seen as either (1) naturally selected (e.g., owing to an increased risk of polyspermy, an increased exposure to sexually transmitted pathogens, and the need to remove a large amount of foreign material from the site of ejaculate receipt), (2) driven by antagonistic coevolution (e.g., avoiding ejaculate-mediated manipulation by the sperm donor), or (3) by sexual selection (e.g., choosing sperm of specific donors). There is thus likely to be a strong incentive for the sperm recipients to control the fate of received substances, and one possible solution is to evolve means of sperm (ejaculate) digestion. There can be no doubt that significant sperm digestion 
L. Schärer et al.

occurs, with well-developed sperm-digesting organs described for example in gastropods (Beeman 1970; Brandriff and Beeman 1973; Beeman 1977; Beese et al. 2006), flatworms (Sluys 1989), and oligochaetes (Westheide 1999). Similarly, even in species with traumatic insemination (see below) that lack specific sperm receiving organs, received sperm appear to be rapidly cleared from recipients (e.g., Macrostomum hystrix; S Ramm, A Schlatter, M Poirier, and L Schärer, unpubl.). Although we expect a net fitness benefit to sperm digestion (otherwise it could not have evolved), what is less clear to date is whether sperm recipients can actually recoup any net nutritional benefit from sperm digestion (it could, at least initially, also occur at a net energetic cost). This is an important empirical question, because some recent arguments for mating conflict resolution based on sperm trading assume such a nutritional benefit ("opportunistic male hypothesis") (Greeff and Michiels 1999; Michiels et al. 2003; see also Yamaguchi et al. 2012).

Any hurdle to fertilization that the sperm recipient erects (i.e., any resistance trait, sensu Rowe et al. 2005) is expected to lead to counterselection on sperm donors to overcome these defenses and is likely to lead to paternity being biased toward particular ( persistent) sperm donors (leading to cryptic female choice, sensu Pitnick and Brown 2000). A number of potential mechanisms for cryptic female choice have been proposed. These include the differential storage and usage of sperm from multiple sperm storage tubules (Baur 2007; but see Koemtzopoulos and Staikou 2007), the postmating "suck" behavior of $M$. lignano already mentioned above (Schärer et al. 2004; Vizoso et al. 2010; Marie-Orleach et al. 2013), and the blocking and phagocytosis of received self-sperm and certain allosperm in the oviduct, and thus preferential fertilization by allosperm from "preferred" clones in the spermcasting ascidian Diplosoma listerianum (Bishop 1996; Bishop et al. 1996; Pemberton et al. 2004). Sperm recipients may also retain more control of sperm uptake, and hence paternity outcomes, when transfer occurs via the external exchange of spermatophores (e.g., in the nudibranch Aeolidiella glauca) (Haase and Karlsson 2000; Karlsson and Haase 2002; see also Bishop and Pemberton 2006). Again, though, it is not clear in all of these cases whether or precisely how the sperm recipient gains direct or indirect fitness benefits from exerting control.

Finally, should sperm recipients gain considerable control over received ejaculates, this could, as originally predicted by Charnov (1979), set the stage for sperm donors to attempt to bypass the ordinary route to fertilization and instead transfer sperm via traumatic insemination into some other part of the recipient's body (e.g., Angeloni 2003; Anthes and Michiels 2007; Schmitt et al. 2007; Smolensky et al. 2009; Schärer et al. 2011; Lange et al. 2012, 2013b; see also Premating Conflicts sections above). Wounding during insemination, and the subsequent need to process/remove ejaculate components transferred in this manner, likely results in significant costs of traumatic insemination to the sperm recipient (e.g., Smolensky et al. 2009; see also Reinhardt et al. 2014). The taxonomic distribution of traumatic insemination suggests that the evolution of this fertilization route is common in simultaneous hermaphrodites (Lange et al. 2013a), but it is currently unclear whether simultaneous hermaphroditism is itself a cause of this bias, as might be expected from theoretical predictions of a greater propensity toward escalated mate harm in hermaphrodites (Michiels and Koene 2006; see also Preece et al. 2009), or whether the pattern arises as a consequence of other common features of simultaneous hermaphrodites such as their tendency to be soft-bodied (Lange et al. 2013a) and/or to possess a high capacity for regeneration.

\section{CONCLUDING REMARKS}

Applying sexual conflict thinking to hermaphrodites is a potentially highly rewarding exercise, both for establishing general principles about sexual conflict and for explaining reproductive diversity among the wide range of taxa exhibiting hermaphroditic sexual systems.

One of our main aims was to show how concepts and ideas normally applied to gono- 
chorists can be adapted to all sexual systems that have resulted from the evolution of anisogamy, and to explore the evolutionary consequences of sexual conflict in sequentially and simultaneously hermaphroditic animals. We hope to have made some progress on at least the first point, but one clear conclusion is that there is considerable scope for further theoretical work exploring just how intralocus and interlocus sexual conflict dynamics differ when they occur in hermaphrodites; we have pointed out some of the most pressing issues.

A recurrent theme throughout this review has been that our ideas about sexual conflict in hermaphrodites and the sort of patterns we would predict as a result currently run some way ahead of the empirical evidence to support or refute them. As we have discussed, even some of the best-established notions-such as gamete trading or sperm digestion-actually have surprisingly limited experimental support. A second major conclusion is thus an appeal for more rigorous testing of the assumptions and predictions of these and other ideas we have discussed across as many different model systems as possible. Specifically, we need to focus future efforts on measuring all relevant costs and benefits to both individuals involved in a particular mating interaction. Moreover, we should focus on measuring these costs and benefits under naturalistic conditions that result in meaningful measures of male, female, and total fitness, ideally using experimental manipulations that permit the collection of causal and not just correlational evidence. This amounts to a significant empirical challenge.

We believe that the combined theoretical and empirical challenge is well worth the effort, given the importance of understanding sexual conflict-not just in the special case of gonochorists - but in the full range of sexual systems in which it actually occurs in nature.

\section{ACKNOWLEDGMENTS}

We thank Bill Rice and Sergey Gavrilets for the opportunity to contribute to this interesting project. We would further like to thank all the participants of a series of hermaphrodite meet- ings over the last several years, with whom we have discussed many of the ideas we have reviewed here, especially Jessica Abbott, Nils Anthes, Patrice David, Joris Koene, Nico Michiels and Dita Vizoso. Moreover, we thank Nils Anthes, Patrice David, Jussi Lehtonen, Lucas Marie-Orleach, Jutta Schneider, Nikolas Vellnow, and Dita Vizoso for providing comments on earlier versions of this article. While writing this article, our work was supported by the Swiss National Science Foundation (grant 31003A143732 to L.S. and grant PA00P3-145375 to T.J.), the Seventh Framework Programme of the European Union (Marie Curie Career Integration Grant to S.A.R.) and the Deutsche Forschungsgemeinschaft (grant RA 2468/1-1 to S.A.R.).

\section{REFERENCES}

* Reference is also in this collection.

Abbott JK. 2011. Intra-locus sexual conflict and sexually antagonistic genetic variation in hermaphroditic animals. Proc R Soc B 278: 161-169.

Adamo SA, Chase R. 1990. The "love dart" of the snail Helix aspersa injects a pheromone that decreases courtship duration. J Exp Zool 255: 80-87.

Andersson M. 1994. Sexual selection. Princeton University Press, Princeton.

Angeloni L. 2003. Sexual selection in a simultaneous hermaphrodite with hypodermic insemination: Body size, allocation to sexual roles and paternity. Anim Behav 66: 417-426.

Anthes N, Michiels NK. 2005. Do "sperm trading” simultaneous hermaphrodites always trade sperm? Behav Ecol 16: 188- 195 .

Anthes N, Michiels NK. 2007. Precopulatory stabbing, hypodermic injections and unilateral copulations in a hermaphroditic sea slug. Biol Lett 3: 121-124.

Anthes N, Putz A, Michiels NK. 2005. Gender trading in a hermaphrodite. Curr Biol 15: R792-R793.

Anthes N, Putz A, Michiels NK. 2006a. Hermaphrodite sex role preferences: The role of partner body size, mating history and female fitness in the sea slug Chelidonura sandrana. Behav Ecol Sociobiol 60: 359-367.

Anthes N, Putz A, Michiels NK. 2006b. Sex role preferences, gender conflict, and sperm trading in simultaneous hermaphrodites: A new framework. Anim Behav 72: 1-12.

Anthes N, Schulenburg H, Michiels NK. 2008. Evolutionary links between reproductive morphology, ecology and mating behavior in opisthobranch gastropods. Evolution 62: 900-916.

Anthes N, David P, Auld JR, Hoffer JNA, Jarne P, Koene JM, Kokko H, Lorenzi MC, Pélissié B, Sprenger D, et al. 2010. Bateman gradients in hermaphrodites: An extended ap- 
L. Schärer et al.

proach to quantify sexual selection. Am Nat 173: 249 263.

Arnold SJ. 1994. Bateman's principles and the measurement of sexual selection in plants and animals. Am Nat 144: S126-S149.

Arnold SJ, Duvall D. 1994. Animal mating systems: A synthesis based on selection theory. Am Nat 143: 317 348.

Arnqvist G, Rowe L. 2005. Sexual conflict. Princeton University Press, Princeton, NJ.

Axelrod R, Hamilton WD. 1981. The evolution of cooperation. Science 211: 1390-1396.

Bateman AJ. 1948. Intra-sexual selection in Drosophila. Heredity 2: $349-368$.

Baur B. 1998. Sperm competition in molluscs. In Sperm competition and sexual selection (ed. Birkhead TR, Møller AP), pp. 255-305. Academic, New York.

Baur B. 2007. Reproductive biology and mating conflict in the simultaneously hermaphroditic land snail Arianta arbustorum. Am Malacol Bull 23: 157-172.

Baur B, Locher R, Baur A. 1998. Sperm allocation in the simultaneously hermaphroditic land snail Arianta arbustorum. Anim Behav 56: 839-845.

Bedhomme S, Bernasconi G, Koene JM, Lankinen A, Arathi HS, Michiels NK, Anthes N. 2009. How does breeding system variation modulate sexual antagonism? Biol Lett 5: 717-720.

Beeman RD. 1970. An autoradiographic study of sperm exchange and storage in a sea hare, Phyllaplysia taylori, a hermaphroditic gastropod (Opisthobranchia: Anaspidea). J Exp Zool 175: 125-132.

Beeman RD. 1977. Gastropoda: Opisthobranchia. In Reproduction in marine invertebrates (ed. Giese AC, Pearse JA), pp. 115-179. Academic, New York.

Beese K, Beier K, Baur B. 2006. Bursa tract diverticulum in the hermaphroditic land snail Arianta arbustorum (Stylommatophora: Helicidae): Morphology, function, and evolutionary implications. J Morphol 267: 940-953.

Beese K, Armbruster GFJ, Beier K, Baur B. 2009. Evolution of female sperm-storage organs in the carrefour of stylommatophoran gastropods. J Zool Syst Evol Res 47: 4960.

Benke M, Reise H, Montagne-Wajer K, Koene JM. 2010. Cutaneous application of an accessory-gland secretion after sperm exchange in a terrestrial slug (Mollusca: Pulmonata). Zoology 113: 118-124.

Bernasconi G, Ashman TL, Birkhead TR, Bishop JDD, Grossniklaus U, Kubli E, Marshall DL, Schmid B, Skogsmyr I, Snook RR, et al. 2004. Evolutionary ecology of the prezygotic stage. Science 303: 971-975.

Bishop JDD. 1996. Female control of paternity in the internally fertilizing compound ascidian Diplosoma listerianum: I. Autoradiographic investigation of sperm movements in the female reproductive tract. Proc $R$ Soc B 263: 369-376.

Bishop JDD, Pemberton AJ. 2006. The third way: Spermcast mating in sessile marine invertebrates. Integr Comp Biol 46: $398-406$.

Bishop JDD, Jones CS, Noble LR. 1996. Female control of paternity in the internally fertilizing compound ascidian
Diplosoma listerianum: II. Investigation of male mating success using RAPD markers. Proc R Soc B 263: 401-407.

Brandriff B, Beeman R. 1973. Observations on the gametolytic gland in the anaspidean opisthobranchs, Phyllaplysia taylori and Aplysia californica. J Morphol 141: 395409.

Chapman T, Arnqvist G, Bangham J, Rowe L. 2003. Sexual conflict. Trends Ecol Evol 18: 41-47.

Charnov EL. 1979. Simultaneous hermaphroditism and sexual selection. Proc Natl Acad Sci 76: 2480-2484.

Charnov EL. 1980. Sex allocation and local mate competition in barnacles. Mar Bio Lett 1: 269-272.

Charnov EL. 1982. The theory of sex allocation. Princeton University Press, Princeton, NJ.

Charnov EL, Maynard Smith J, Bull JJ. 1976. Why be an hermaphrodite? Nature 263: 125-126.

Chase R. 2007. The function of dart shooting in helicid snails. Am Malacol Bull 23: 183-189.

Chase R, Blanchard KC. 2006. The snail's love-dart delivers mucus to increase paternity. Proc $R$ Soc B 273: 14711475.

Chase R, Vaga K. 2006. Independence, not conflict, characterizes dart-shooting and sperm exchange in a hermaphroditic snail. Behav Ecol Sociobiol 59: 732-739.

Collin R, McLellan M, Gruber K, Bailey-Jourdain C. 2005. Effects of conspecific associations on size at sex change in three species of calyptraeid gastropods. Mar Ecol Prog Ser 293: 89-97.

Connor RC. 1992. Egg-trading in simultaneous hermaphrodites: An alternative to tit-for-tat. J Evol Biol 5: 523528.

Crowley PH, Hart MK. 2007. Evolutionary stability of egg trading and parceling in simultaneous hermaphrodites: The chalk bass revisited. J Theor Biol 246: 420-429.

Crowley PH, Cottrell T, Garcia T, Hatch M, Sargent RC, Stokes BJ, White JM. 1998. Solving the complementarity dilemma: Evolving strategies for simultaneous hermaphroditism. J Theor Biol 195: 13-26.

Darwin C. 1876. The effects of cross and self-fertilisation in the vegetable kingdom. John Murray, London.

Davison A, Wade CM, Mordan PB, Chiba S. 2005. Sex and darts in slugs and snails (Mollusca: Gastropoda: Stylommatophora). J Zool 267: 329-338.

Dawkins R. 1976. The selfish gene. Oxford University Press, Oxford.

DeWitt TJ. 1991. Mating behavior of the freshwater pulmonate snail Physa gyrina. Am Malacol Bull 9: 81-84.

DeWitt TJ. 1996. Gender contests in a simultaneous hermaphrodite snail: A size-advantage model for behaviour. Anim Behav 51: 345-351.

Dillen L, Jordaens K, Backeljau T. 2009. Sperm transfer, sperm storage, and sperm digestion in the hermaphroditic land snail Succinea putris (Gastropoda, Pulmonata). Invertebr Biol 128: 97-106.

Dillen L, Jordaens K, van Dongen S, Backeljau T. 2010. Effects of body size on courtship role, mating frequency and sperm transfer in the land snail Succinea putris. Anim Behav 79: 1125-1133.

Domínguez J, Velando A. 2013. Sexual selection in earthworms: Mate choice, sperm competition, differential al- 
location and partner manipulation. Appl Soil Ecol 69: $21-27$.

Dugatkin LA. 1997. Cooperation among animals: An evolutionary perspective. Oxford University Press, Oxford.

Düsing C. 1884. The regulation of the sex ratio. Jenaische Zeitschrift für Naturwissenschaft 17: 593-940.

Eberhard WG. 1985. Sexual selection and animal genitalia. Harvard University Press, Cambridge, MA.

* Edward DA, Stockley P, Hosken DJ. 2014. Sexual conflict and sperm competition. Cold Spring Harb Perspect Biol doi: $10.1101 /$ cshperspect.017707.

Eppley SM, Jesson LK. 2008. Moving to mate: The evolution of separate and combined sexes in multicellular organisms. J Evol Biol 21: 727-736.

Facon B, Ravigné V, Goudet J. 2008. Gender-role alternation in the simultaneously hermaphroditic freshwater snail Physa acuta: Not with the same partner. Behav Ecol Sociobiol 62: 713-720.

Fischer EA. 1980. The relationship between mating system and simultaneous hermaphroditism in the coral reef fish, Hypoplectrus nigricans (Serranidae). Anim Behav 28: 620-633.

Fischer EA. 1984. Egg trading in the chalk bass, Serranus tortugarum, a simultaneous hermaphrodite. Z Tierpsychol 66: 143-151.

Fischer EA. 1987. Mating behavior in the black hamlet gamete trading or egg trading. Env Biol Fish 18: 143-148.

Fischer EA. 1988. Simultaneous hermaphroditism, tit-fortat, and the evolutionary stability of social systems. Ethol Sociobiol 9: 119-136.

Fisher RA. 1930. The genetical theory of natural selection. Oxford University Press, Oxford.

Garefalaki M-E, Triantafyllidis A, Abatzopoulos TJ, Staikou A. 2010. The outcome of sperm competition is affected by behavioural and anatomical reproductive traits in a simultaneously hermaphroditic land snail. $J$ Evol Biol 23: $966-976$.

Ghiselin MT. 1969. The evolution of hermaphroditism among animals. Q Rev Biol 44: 189-208.

Gianguzza P, Badalamenti F, Jensen KR, Chemello R, Cannicci S, Riggio S. 2004. Body size and mating strategies in the simultaneous hermaphrodite Oxynoe olivacea (Mollusca, Opisthobranchia, Sacoglossa). Funct Ecol 18: 899_ 906.

Greeff JM, Michiels NK. 1999. Sperm digestion and reciprocal sperm transfer can drive hermaphrodite sex allocation to equality. Am Nat 153: 421-430.

Haase M, Karlsson A. 2000. Mating and the inferred function of the genital system of the nudibranch, Aeolidiella glauca (Gastropoda: Opisthobranchia: Aeolidioidea). Invertebr Biol 119: 287-298.

Hamilton WD. 1967. Extraordinary sex ratios. Science 156: 477-488.

Hardy ICW, editor. 2002. Sex ratios: Concepts and research methods. Cambridge University Press, Cambridge.

Hart MK, Kratter AW, Svoboda A-M, Lawrence CL, Sargent RC, Crowley PH. 2010. Sex allocation in a group-living simultaneous hermaphrodite: Effects of density at two different spatial scales. Evol Ecol Res 12: 189-202.
Heath DJ. 1979. Brooding and the evolution of hermaphroditism. J Theor Biol 81: 151-155.

Hodgkin J, Barnes TM. 1991. More is not better: Brood size and population growth in a self-fertilizing nematode. Proc R Soc B 246: 19-24.

Hoffer JNA, Schwegler D, Ellers J, Koene JM. 2012. Mating rate influences female reproductive investment in a simultaneous hermaphrodite, Lymnaea stagnalis. Anim Behav 84: 523-529.

Holland B, Rice WR. 1998. Perspective: Chase-away sexual selection: Antagonistic seduction versus resistance. Evolution 52: 1-7.

Houston AI, McNamara JM. 2005. John Maynard Smith and the importance of consistency in evolutionary game theory. Biol Phil 20: 933-950.

Hughes DJ. 1989. Variation in reproductive strategy among clones of the bryozoan Celleporella hyalina. Ecol Monogr 59: 387-403.

Iyer P, Roughgarden J. 2008. Dioecy as a specialization promoting sperm delivery. Evol Ecol Res 10: 867-892.

Janicke T, Schärer L. 2009a. Determinants of mating and sperm-transfer success in a simultaneous hermaphrodite. J Evol Biol 22: 405-415.

Janicke T, Schärer L. 2009b. Sex allocation predicts mating rate in a simultaneous hermaphrodite. Proc $R$ Soc B 276: 4247-4253.

Jarne P, Auld JR. 2006. Animals mix it up too: The distribution of self-fertilization among hermaphroditic animals. Evolution 60: 1816-1824.

Jennions MD, Kokko H. 2010. Sexual selection. In Evolutionary behavioral ecology (eds. Westneat DF, Fox CW), pp. 343-364. Oxford University Press, Oxford.

Jordaens K, Pinceel J, Backeljau T. 2005. Mate choice in the hermaphroditic land snail Succinea putris (Stylommatophora: Succineidae). Anim Behav 70: 329-337.

Karlsson A, Haase M. 2002. The enigmatic mating behaviour and reproduction of a simultaneous hermaphrodite, the nudibranch Aeolidiella glauca (Gastropoda, Opisthobranchia). Can J Zool 80: 260-270.

Kimura K, Chiba S. 2013. Delayed spermatophore removal in the land snail Euhadra peliomphala. Biol J Linn Soc 108: 806-811.

Kimura K, Shibuya K, Chiba S. 2013. The mucus of a land snail love-dart suppresses subsequent matings in darted individuals. Anim Behav 85: 631-635.

Klinkhamer PGL, de Jong TJ. 1997. Size-dependent allocation to male and female reproduction. In Plant resource allocation (ed. Bazzaz FA, Grace J), pp. 211-229. Academic, New York.

Koemtzopoulos E, Staikou A. 2007. Variation in spermathecal morphology is independent of sperm competition intensity in populations of the simultaneously hermaphroditic land snail Cornu aspersum. Zoology 110: 139-146.

Koene JM. 2005. Allohormones and sensory traps: A fundamental difference between hermaphrodites and gonochorists? Invertebr Reprod Dev 48: 101-107.

Koene JM. 2006. Tales of two snails: Sexual selection and sexual conflict in Lymnaea stagnalis and Helix aspersa. Integr Comp Biol 46: 419-429. 


\section{Schärer et al.}

Koene JM, Chase R. 1998. Changes in the reproductive system of the snail Helix aspersa caused by mucus from the love dart. J Exp Biol 201: 2313-2319.

Koene JM, Schulenburg H. 2005. Shooting darts: Co-evolution and counter-adaptation in hermaphroditic snails. BMC Evol Biol 5: 25.

Koene JM, ter Maat A. 2001. "Allohormones": A class of bioactive substances favoured by sexual selection. $J$ Comp Physiol A 187: 323-326.

Koene JM, ter Maat A. 2005. Sex role alternation in the simultaneously hermaphroditic pond snail Lymnaea stagnalis is determined by the availability of seminal fluid. Anim Behav 69: 845-850.

Koene JM, Sundermann G, Michiels NK. 2002. On the function of body piercing during copulation in earthworms. Invertebr Reprod Dev 41: 35-40.

Koene JM, Pförtner T, Michiels NK. 2005. Piercing the partner's skin influences sperm uptake in the earthworm Lumbricus terrestris. Behav Ecol Sociobiol 59: 243-249.

Koene JM, Montagne-Wajer K, ter Maat A. 2006. Effects of frequent mating on sex allocation in the simultaneously hermaphroditic great pond snail (Lymnaea stagnalis). Behav Ecol Sociobiol 60: 332-338.

Koene JM, Brouwer A, Hoffer JNA. 2009. Reduced egg laying caused by a male accessory gland product opens possibility for sexual conflict in a simultaneous hermaphrodite. Anim Biol 59: 435-448.

Koene JM, Sloot W, Montagne-Wajer K, Cummins SF, Degnan BM, Smith JS, Nagle GT, ter Maat A. 2010. Male accessory gland protein reduces egg laying in a simultaneous hermaphrodite. PLoS ONE 5: e10117.

Koene JM, Liew T-S, Montagne-Wajer K, Schilthuizen M. 2013. A syringe-like love dart injects male accessory gland products in a tropical hermaphrodite. PLOS ONE 8: e69968.

Kokko H, Klug H, Jennions MD. 2012. Unifying cornerstones of sexual selection: Operational sex ratio, Bateman gradient and the scope for competitive investment. Ecol Lett 15: 1340-1351.

König S, Mehlich A-M, Bullesbach J, Michiels NK. 2006. Allohormones in Lumbricus terrestris? Mass spectrometry of the setal gland product indicates possible role of ubiquitin. Invertebr Reprod Dev 49: 103-112.

Landolfa MA. 2002. On the adaptive function of gamete trading in the black hamlet Hypoplectrus nigricans. Evol Ecol Res 4: 1191-1199.

Landolfa MA, Green DM, Chase R. 2001. Dart shooting influences paternal reproductive success in the snail Helix aspersa (Pulmonata, Stylommatophora). Behav Ecol 12: 773-777.

Lange R, Gerlach T, Beninde J, Werminghausen J, Reichel V, Anthes N. 2012. Female fitness optimum at intermediate mating rates under traumatic mating. PLOS ONE 8: 8 .

Lange R, Reinhardt K, Michiels NK, Anthes N. 2013a. Functions, diversity, and evolution of traumatic mating. Biol Rev 88: 585-601.

Lange R, Werminghausen J, Anthes N. 2013b. Does traumatic secretion transfer manipulate mating roles or reproductive output in a hermaphroditic sea slug? Behav Ecol Sociobiol 67: 1239-1247.
Lange R, Werminghausen J, Anthes N. 2014. Cephalo-traumatic secretion transfer in a hermaphrodite sea slug. Proc $R$ Soc B 281: 20132424.

Lankinen $\AA$, Larsson MC. 2009. Conflicting selection pressures on reproductive functions and speciation in plants. Evol Ecol 23: 147-157.

Lehtonen J, Kokko H. 2011. Two roads to two sexes: Unifying gamete competition and gamete limitation in a single model of anisogamy evolution. Behav Ecol Sociobiol 65: $445-459$.

Leonard JL. 1990. The hermaphrodite's dilemma. J Theor Biol 147: 361-372.

Leonard J. 1999. Modern portfolio theory and the prudent hermaphrodite. Invertebr Reprod Dev 36: 129-135.

Leonard JL. 2005. Bateman's principle and simultaneous hermaphrodites: A paradox. Integr Comp Biol 45: 856873.

Leonard JL. 2006. Sexual selection: Lessons from hermaphrodite mating systems. Integr Comp Biol 46: 349-367.

Leonard JL, Lukowiak K. 1984. Male-female conflict in a simultaneous hermaphrodite resolved by sperm trading. Am Nat 124: 282-286.

Leonard JL, Lukowiak K. 1985. Courtship, copulation, and sperm trading in the sea slug, Navanax inermis (Opisthobranchia: Cephalaspidea). Can J Zool 63: 2719-2729.

Leonard JL, Lukowiak K. 1991. Sex and the simultaneous hermaphrodite: Testing models of male-female conflict in a sea slug, Navanax intermis (Opisthobranchia). Anim Behav 41: 255-266.

Lessells CM, Snook RR, Hosken DJ. 2009. The evolutionary origin and maintenance of sperm: Selection for a small, motile gamete mating type. In Sperm biology: An evolutionary perspective (ed. Birkhead TR, Hosken DJ, Pitnick S), pp. 69-149. Academic, San Diego.

Lorenzi MC, Sella G. 2008. A measure of sexual selection in hermaphroditic animals: Parentage skew and the opportunity for selection. J Evol Biol 21: 827-833.

Ludwig AN, Walsh PJ. 2008. Multiple mating, sperm storage, and mating preference in Aplysia californica. Biol Bull 215: 365-271.

Madjidian JA, Hydbom S, Lankinen A. 2012. Influence of number of pollinations and pollen load size on maternal fitness costs in Collinsia heterophylla: Implications for existence of a sexual conflict over timing of stigma receptivity. J Evol Biol 25: 1623-1635.

Marie-Orleach L, Janicke T, Schärer L. 2013. Effects of mating status on copulatory and postcopulatory behaviour in a simultaneous hermaphrodite. Anim Behav 85: 453461.

Marsh-Hunkin KE, Heinz HM, Hawkins MB, Godwin J. 2013. Estrogenic control of behavioral sex change in the bluehead wrasse, Thalassoma bifasciatum. Integr Comp Biol 53: 951-959.

Michiels NK. 1998. Mating conflicts and sperm competition in simultaneous hermaphrodites. In Sperm competition and sexual selection (ed. Birkhead TR, Møller AP), pp. 219-254. Academic, San Diego.

Michiels NK, Bakovski B. 2000. Sperm trading in a hermaphroditic flatworm: Reluctant fathers and sexy mothers. Anim Behav 59: 319-325. 
Michiels NK, Koene JM. 2006. Sexual selection favors harmful mating in hermaphrodites more than in gonochorists. Integr Comp Biol 46: 473-480.

Michiels NK, Newman LJ. 1998. Sex and violence in hermaphrodites. Nature 391: 647.

Michiels NK, Streng A. 1998. Sperm exchange in a simultaneous hermaphrodite. Behav Ecol Sociobiol 42: 171-178.

Michiels NK, Raven-Yoo-Heufes A, Brockmann KK. 2003. Sperm trading and sex roles in the hermaphroditic opisthobranch sea slug Navanax inermis: Eager females or opportunistic males? Biol J Linn Soc 78: 105-116.

Munday PL, Buston PM, Warner RR. 2006a. Diversity and flexibility of sex-change strategies in animals. Trends Ecol Evol 21: 89-95.

Munday PL, White JW, Warner RR. 2006b. A social basis for the development of primary males in a sex-changing fish. Proc R Soc B 273: 2845-2851.

Nakadera Y, Koene JM. 2013. Reproductive strategies in hermaphroditic gastropods: Conceptual and empirical approaches. Can J Zool 91: 367-381.

Nakadera Y, Swart EM, Hoffer JNA, den Boon O, Ellers J, Koene JM. 2014. Receipt of seminal fluid proteins causes reduction of male investment in a simultaneous hermaphrodite. Curr Biol 24: 859-862.

Parker GA. 1970. Sperm competition and its evolutionary consequences in the insects. Biol Rev 45: 525-567.

Parker GA. 1978. Selection on nonrandom fusion of gametes during evolution of anisogamy. J Theor Biol 73: 128

Parker GA. 1979. Sexual selection and sexual conflict. In Sexual selection and reproductive competition in insects (ed. Blum MS, Blum NA), pp. 123-166. Academic, San Diego.

Parker GA. 2006. Sexual conflict over mating and fertilisation: An overview. Phil Trans R Soc B 361: 235-260.

Parker GA. 2011. The origin and maintenance of two sexes (anisogamy), and their gamete sizes by gamete competition. In The evolution of anisogamy: A fundamental phenomenon underlying sexual selection (ed. Togashi T, Cox PA), pp. 17-74. Cambridge University Press, Cambridge.

* Parker GA. 2014. The sexual cascade and the rise of preejaculatory (Darwinian) sexual selection, sex roles, and sexual conflict. Cold Spring Harb Perspect Biol doi: 10.1101/cshperspect.017509.

Parker GA, Birkhead TR. 2013. Polyandry: The history of a revolution. Phil Trans R Soc B 368: 20120335.

Parker GA, Smith VGF, Baker RR. 1972. Origin and evolution of gamete dimorphism and male-female phenomenon. J Theor Biol 36: 529-553.

Pauly D, Christensen V. 1995. Primary production required to sustain global fisheries. Nature 374: 255-257.

Pélissié B, Jarne P, David P. 2012. Sexual selection without sexual dimorphism: Bateman gradients in a simultaneous hermaphrodite. Evolution 66: 66-81.

Pemberton AJ, Sommerfeldt AD, Wood CA, Flint HC, Noble LR, Clarke KR, Bishop JDD. 2004. Plant-like mating in an animal: Sexual compatibility and allocation tradeoffs in a simultaneous hermaphrodite with remote transfer of sperm. J Evol Biol 17: 506-518.
Petersen CW. 1995. Reproductive behavior, egg trading, and correlates of male mating success in the simultaneous hermaphrodite, Serranus tabacarius. Env Biol Fish 43: 351-361.

Petersen CW. 2006. Sexual selection and reproductive success in hermaphroditic seabasses. Integr Comp Biol 46: 439-448.

Pitnick S, Brown WD. 2000. Criteria for demonstrating female sperm choice. Evolution 54: 1052-1056.

Preece T, Mao Y, Garrahan JP, Davison A. 2009. Harmful mating tactics in hermaphrodites. Am Nat 173: 632-639.

Pressley PH. 1981. Pair formation and joint territoriality in a simultaneous hermaphrodite: The coral reef fish Serranus tigrinus. Z Tierpsychol 56: 33-46.

Puurtinen M, Kaitala V. 2002. Mate-search efficiency can determine the evolution of separate sexes and the stability of hermaphroditism in animals. Am Nat 160: 645-660.

* Reinhardt K, Anthes N, Lange R. 2014. Copulatory wounding and traumatic insemination. Cold Spring Harb Perspect Biol doi: 10.1101/cshperspect.017582.

Reise H. 2007. A review of mating behavior in slugs of the genus Deroceras (Pulmonata: Agriolimacidae). Am Malacol Bull 23: 137-156.

Reise H, Visser S, Hutchinson JMC. 2007. Mating behaviour in the terrestrial slug Deroceras gorgonium: Is extreme morphology associated with extreme behaviour? Anim Biol 57: 197-215.

Renner SS, Ricklefs RE. 1995. Dioecy and its correlates in the flowering plants. Am J Bot 82: 596-606.

Rice WR, Chippindale AK. 2001. Intersexual ontogenetic conflict. J Evol Biol 14: 685-693.

Rice WR, Holland B. 1997. The enemies within: Intergenomic conflict, interlocus contest evolution (ICE), and the intraspecific Red Queen. Behav Ecol Sociobiol 41: 1-10.

Rice WR, Stewart AD, Morrow EH, Linder JE, Orteiza N, Byrne PG. 2006. Assessing sexual conflict in the Drosophila melanogaster laboratory model system. Phil Trans $R$ Soc B 361: 287-299.

Riesgo A, Novo M, Sharma PP, Peterson M, Maldonado M, Giribet G. 2014. Inferring the ancestral sexuality and reproductive condition in sponges (Porifera). Zool Scr 43: $1-17$.

Robertson DR. 1972. Social control of sex reversal in a coral reef fish. Science 177: 1007-1009.

Rogers DW, Chase R. 2001. Dart receipt promotes sperm storage in the garden snail Helix aspersa. Behav Ecol Sociobiol 50: $122-127$.

Rogers DW, Chase R. 2002. Determinants of paternity in the garden snail Helix aspersa. Behav Ecol Sociobiol 52: 289295.

Rowe L, Cameron E, Day T. 2005. Escalation, retreat, and female indifference as alternative outcomes of sexually antagonistic coevolution. Am Nat 165: S5-S18.

Ryan JF, Pang K, Schnitzler CE, Nguyen A-D, Moreland RT, Simmons DK, Koch BJ, Francis WR, Havlak P, Program NCS, et al. 2013. The genome of the ctenophore Mnemiopsis leidyi and its implications for cell type evolution. Science 342: 1242592. 
L. Schärer et al.

Sauer J, Hausdorf B. 2009. Sexual selection is involved in speciation in a land snail radiation on Crete. Evolution 63: $2535-2546$.

Schärer L. 2009. Tests of sex allocation theory in simultaneously hermaphroditic animals. Evolution 63: 13771405.

Schärer L. 2014. Evolution: Don't be so butch, dear! Curr Biol 24: R311-R313.

Schärer L, Janicke T. 2009. Sex allocation and sexual conflict in simultaneously hermaphroditic animals. Biol Lett 5: 705-708.

Schärer L, Pen I. 2013. Sex allocation and investment into pre- and postcopulatory traits in simultaneous hermaphrodites: The role of polyandry and local sperm competition. Phil Trans R Soc Lond B 368: 20120052.

Schärer L, Karlsson LM, Christen M, Wedekind C. 2001. Size-dependent sex allocation in a simultaneous hermaphrodite parasite. J Evol Biol 14: 55-67.

Schärer L, Joss G, Sandner P. 2004. Mating behaviour of the marine turbellarian Macrostomum sp.: These worms suck. Mar Biol 145: 373-380.

Schärer L, Littlewood DTJ, Waeschenbach A, Yoshida W, Vizoso DB. 2011. Mating behaviour and the evolution of sperm design. Proc Natl Acad Sci 108: 1490-1495.

Schärer L, Rowe L, Arnqvist G. 2012. Anisogamy, chance and the evolution of sex roles. Trends Ecol Evol 27: 260-264.

Schmitt V, Anthes N, Michiels NK. 2007. Mating behaviour in the sea slug Elysia timida (Opisthobranchia, Sacoglossa): Hypodermic injection, sperm transfer and balanced reciprocity. Front Zool 4: 17.

Schultz ET, Warner RR. 1991. Phenotypic plasticity in lifehistory traits of female Thalassoma bifasciatum (Pisces: Labridae): 2. Correlation of fecundity and growth rate in comparative studies. Env Biol Fish 30: 333-344.

Sekizawa A, Seki S, Tokuzato M, Shiga S, Nakashima Y. 2013 Disposable penis and its replenishment in a simultaneous hermaphrodite. Biol Lett 9: 20121150.

Sella G. 1985. Reciprocal egg trading and brood care in a simultaneous polychaete worm. Anim Behav 33: $938-$ 944.

Sella G. 1988. Reciprocation, reproductive success, and safeguards against cheating in a hermaphroditic polycheate worm, Ophryotrocha diadema Åkesson, 1976. Biol Bull 175: 212-217.

Sella G, Lorenzi MC. 2000. Partner fidelity and egg reciprocation in the simultaneously hermaphroditic polychaete worm Ophryotrocha diadema. Behav Ecol 11: 260264.

Sella G, Ramella L. 1999. Sexual conflict and mating systems in the dorvilleid genus Ophryotrocha and the dinophilid genus Dinophilus. Hydrobiologia 402: 203-213.

Sella G, Premoli MC, Turri F. 1997. Egg trading in the simultaneously hermaphroditic polychaete worm Ophryotrocha gracilis (Huth). Behav Ecol 8: 83-86.

Shuster SM, Wade MJ. 2003. Mating systems and strategies. Princeton University Press, Princeton, NJ.

* Sirot LK, Wong A, Chapman T, Wolfner MF. 2014. Sexual conflict and seminal fluid proteins: A dynamic landscape of sexual interactions. Cold Spring Harb Perspect Biol doi: 10.1101/cshperspect.017533.
Sluys R. 1989. Sperm resorption in triclads (Platyhelminthes, Tricladida). Invertebr Reprod Dev 15: 89-95.

Smolensky N, Romero MR, Krug PJ. 2009. Evidence for costs of mating and self-fertilization in a simultaneous hermaphrodite with hypodermic insemination, the opisthobranch Alderia willowi. Biol Bull 216: 188-199.

Sprenger D, Faber J, Michiels NK, Anthes N. 2008. Natural female mating rate maximizes hatchling size in a marine invertebrate. J Anim Ecol 77: 696-701.

Sprenger D, Dingemanse NJ, Dochtermann NA, Theobald J, Walker SPW. 2012. Aggressive females become aggressive males in a sex-changing reef fish. Ecol Lett 15: 986-992.

Thornhill R. 1983. Cryptic female choice and its implications in the scorpionfly Harpobittacus nigriceps. Am Nat 122: $765-788$.

Togashi T, Cox PA. 2011. The evolution of anisogamy: A fundamental phenomenon underlying sexual selection. Cambridge University Press, Cambridge.

Tomlinson J. 1966. The advantage of hermaphroditism and parthenogenesis. J Theor Biol 11: 54-58.

Trivers RL. 1972. Parental investment and sexual selection. In Sexual selection and the descent of man 1871-1971 (ed. Campbell B), pp. 136-179. Aldine, Chicago.

Trivers RL. 1974. Parent-offspring conflict. Amer Zool 14: 249-264.

Vahed K. 1998. The function of nuptial feeding in insects: A review of empirical studies. Biol Rev 73: 43-78.

Van Duivenboden YA, Pieneman AW, ter Maat A. 1985. Multiple mating suppresses fecundity in the hermaphrodite freshwater snail Lymnaea stagnalis: A laboratory study. Anim Behav 33: 1184-1191.

Velando A, Eiroa J, Domínguez J. 2008. Brainless but not clueless: Earthworms boost their ejaculates when they detect fecund non-virgin partners. Proc $R$ Soc $B$ 275: 1067-1072.

Vizoso DB, Rieger G, Schärer L. 2010. Goings-on inside a worm: Functional hypotheses derived from sexual conflict thinking. Biol J Linn Soc 99: 370-383.

Vreys C, Michiels NK. 1997. Flatworms flatten to size up each other. Proc R Soc B 264: 1559-1564.

Warner RR. 1975. The adaptive significance of sequential hermaphroditism in animals. Am Nat 109: 61-82.

Warner RR. 1984. Deferred reproduction as a response to sexual selection in a coral reef fish: A test of the life historical consequences. Evolution 38: 148-162.

Warner RR, Hoffman SG. 1980. Local population size as a determinant of mating system and sexual composition in two tropical marine fishes (Thalassoma spp.). Evolution 34: 508-518.

Warner RR, Swearer SE. 1991. Social control of sex change in the bluehead wrasse, Thalassoma bifasciatum (Pisces: Labridae). Biol Bull 181: 199-204.

Warner RR, Shapiro DY, Marconato A, Petersen CW. 1995. Sexual conflict: Males with highest mating success convey the lowest fertilization benefits to females. Proc $R$ Soc Lond B 262: 135-139.

Weeks SC. 2012. The role of androdioecy and gynodioecy in mediating evolutionary transitions between dioecy and 
hermaphroditism in the Animalia. Evolution 66: 36703686.

West SA. 2009. Sex allocation. Princeton University Press, Princeton, NJ.

Westheide W. 1999. Ultrastructure and functional significance of intestinojunctional spermathecae in enchytraeids (Oligochaeta, Annelida). Hydrobiologia 406: 199-211.

Wethington AR, Dillon RT Jr. 1996. Gender choice and gender conflict in a non-reciprocally mating simultaneous hermaphrodite, the freshwater snail, Physa. Anim Behav 51: 1107-1118.
Yamaguchi S, Sawada K, Nakashima Y, Takahashi S. 2012. Sperm as a paternal investment: A model of sex allocation in sperm-digesting hermaphrodites. Theor Ecol 5: 99103.

Yund PO, Marcum Y, Stewart-Savage J. 1997. Life-history variation in a colonial ascidian: Broad-sense heritabilities and tradeoffs in allocation to asexual growth and male and female reproduction. Biol Bull 192: 290 299.

Zizzari ZV, Smolders I, Koene JM. 2014. Alternative delivery of male accessory gland products. Front Zoo 11: 32 . 


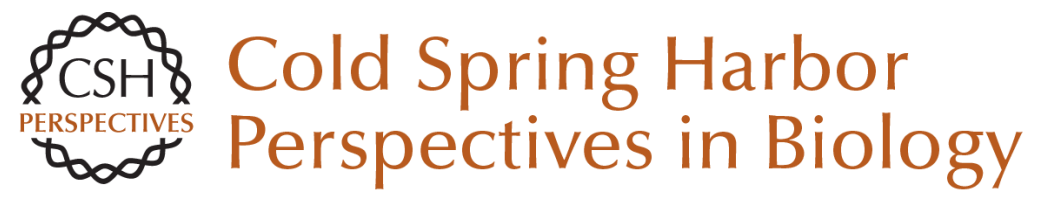

\section{Sexual Conflict in Hermaphrodites}

Lukas Schärer, Tim Janicke and Steven A. Ramm

Cold Spring Harb Perspect Biol 2015; doi: 10.1101/cshperspect.a017673 originally published online September 18, 2014

\section{Subject Collection The Genetics and Biology of Sexual Conflict}

Mechanisms and Evidence of Genital Coevolution: The Roles of Natural Selection, Mate Choice, and Sexual Conflict

Patricia L.R. Brennan and Richard O. Prum

The Evolution of Sexually Antagonistic Phenotypes

Jennifer C. Perry and Locke Rowe

Reproductive Parasitism: Maternally Inherited

Symbionts in a Biparental World

Gregory D.D. Hurst and Crystal L. Frost

Sex-Biased Gene Expression and Sexual Conflict throughout Development

Fiona C. Ingleby, Ilona Flis and Edward H. Morrow

Human Homosexuality: A Paradigmatic Arena for

Sexually Antagonistic Selection?

Andrea Camperio Ciani, Umberto Battaglia and Giovanni Zanzotto

Sexual Conflict Arising from Extrapair Matings in Birds

Alexis S. Chaine, Robert Montgomerie and Bruce E. Lyon

Sexual Conflict and Seminal Fluid Proteins: A

Dynamic Landscape of Sexual Interactions

Laura K. Sirot, Alex Wong, Tracey Chapman, et al.

Conflict on the Sex Chromosomes: Cause, Effect, and Complexity

Judith E. Mank, David J. Hosken and Nina Wedell
Infanticide as Sexual Conflict: Coevolution of

Male Strategies and Female Counterstrategies Ryne A. Palombit

Copulatory Wounding and Traumatic Insemination

Klaus Reinhardt, Nils Anthes and Rolanda Lange

Sexual Conflict in Hermaphrodites

Lukas Schärer, Tim Janicke and Steven A. Ramm

Sexual Conflict and Sperm Competition

Dominic A. Edward, Paula Stockley and David J. Hosken

Sexually Antagonistic Zygotic Drive: A New Form of Genetic Conflict between the Sex

Chromosomes Urban Friberg and William R. Rice

Sex Chromosome Drive

Quentin Helleu, Pierre R. Gérard and Catherine Montchamp-Moreau

Is Sexual Conflict an "Engine of Speciation"? Sergey Gavrilets

Sexual Cannibalism as a Manifestation of Sexual Conflict

Jutta M. Schneider

For additional articles in this collection, see http://cshperspectives.cshlp.org/cgi/collection/

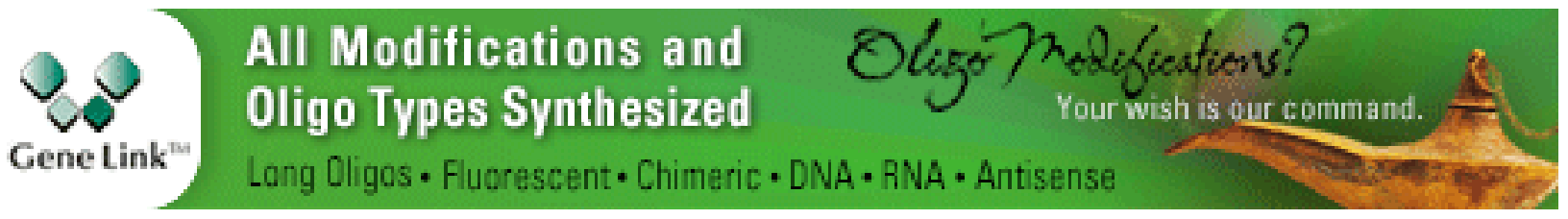

Copyright @ 2015 Cold Spring Harbor Laboratory Press; all rights reserved 
For additional articles in this collection, see http://cshperspectives.cshlp.org/cgi/collection/

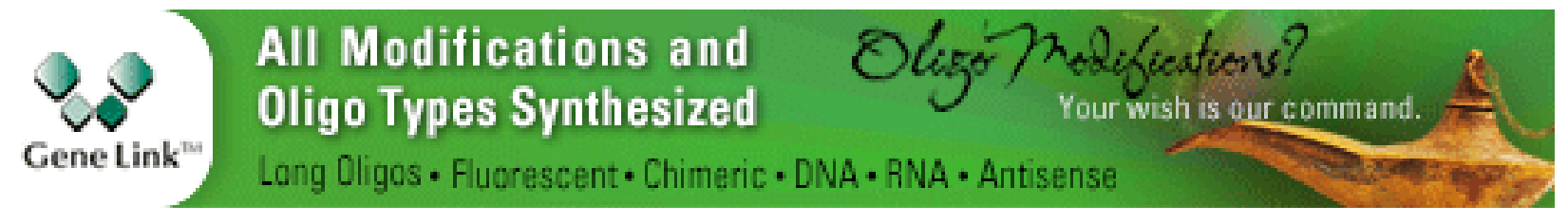

Copyright @ 2015 Cold Spring Harbor Laboratory Press; all rights reserved 